\title{
EL USO DE IMÁGENES LÍDAR EN COSTA RICA: CASOS DE ESTUDIO APLICADOS EN GEOLOGÍA, INGENIERÍA Y ARQUEOLOGÍA
}

\author{
THE USE OF LIDAR IMAGES IN COSTA RICA: CASE STUDIES APLIED \\ IN GEOLOGY, ENGINNEERING, AND ARCHEOLOGY
}

\author{
Paulo Ruiz ${ }^{1 *}$, José F. Garroํ, Gerardo J. Soto ${ }^{2}$ \\ ${ }^{1}$ Laboratorio Nacional de Materiales y Modelos Estructurales, \\ Universidad de Costa Rica; LANAMME-UCR \\ ${ }^{2}$ Terra Cognita Consultores S.A. \\ *Autor para contacto: paulo.ruizcubillo@ucr.ac.cr
}

(Recibido: 10/06/2014; aceptado: 23/10/2014)

\begin{abstract}
We present a review about lidar technology evolution, it's improvements and additions from other technologies in the last 15 years. Also, we show data regarding the operation of aerial and terrestrial lídar equipment, technical parameters for data acquisition and examples from different data resolutions. We present the results from four case studies in Costa Rica: 1) the finding of pre-hispanic trials near Arenal volcano. 2) A case of geologic mapping and the finding of new volcanic structures in the north flank of Poás volcano. 3) The characterization of a landslide near Palmares that represents a hazard for the road network and 4) a detail survey of a pre-hispanic stone sphere. In the following years, the results from new lídar studies (terrestrial, aerial and/or both) will become more frequent, because its cost will be more affordable, and the transference of data between institutions will generate new applications in different research fields.
\end{abstract}

Keywords: Lidar, geology, archeology, landslides, Pre-Hispanic sphere.

\begin{abstract}
RESUMEN: Se hace una reseña histórica sobre la evolución de la tecnología lídar, sus mejoras y adiciones de otras tecnologías en los últimos 15 años. Presentamos información del funcionamiento de lídar terrestre y aéreo, parámetros técnicos para la adquisición de datos y sus resoluciones. Se exponen los resultados de 4 estudios en Costa Rica: 1) El descubrimiento de trillos precolombinos en el sector del volcán Arenal 2) Un caso de mapeo geológico y hallazgo de estructuras volcánicas, en la zona norte del volcán Poás 3) La caracterización de un deslizamiento cerca de Palmares que representa una amenaza a la red vial y 4.) Un levantamiento en detalle de una esfera precolombina. En los próximos años, los resultados de lídar van a ser más frecuentes debido a que sus costos serán más accesibles, se facilitaría la transferencia de información entre instituciones y existirán nuevas aplicaciones en diferentes campos.

Palabras clave: Lídar, geología, arqueología, deslizamientos, esfera precolombina.
\end{abstract}




\section{INTRODUCCIÓN}

\section{Tecnología lídar}

La palabra lídar proviene del acrónimo en inglés Laser Imaging Detection and Ranging, que en español se podría expresar como "detección de imágenes por láser y distancia”. Se trata de una tecnología de sensores remotos con múltiples usos, de los cuales los más frecuentes son cartografiar la topografía de superficies extensas cuando es aerotransportado, o bien pequeñas zonas u objetos cuando se usa en tierra. Existe desde hace varias décadas, pero ha sido en los últimos quince años que al complementarse con otras tecnologías (GPS, computadoras personales poderosas, fotografía digital de gran formato, y software amigable) ha evolucionado hasta el punto de poder generar modelos de elevación digital (MED) con niveles de detalle y resolución en el orden de centímetros a milímetros.

El fundamento de la tecnología lídar está en medir distancias iluminando un objetivo con un rayo láser y posteriormente analizando la luz reflejada e información generada en ese objetivo. Cada dato o punto generado con lídar por sí solo no tiene mucha utilidad; sin embargo al unir los millones de puntos generados a partir de un barrido con un escáner láser en un área específica, se pueden recrear superficies en tres dimensiones con las que posteriormente se puede trabajar.

Esta tecnología tuvo pocas aplicaciones inicialmente, y estuvo restringida a los campos de la milicia y la meteorología. Actualmente se utiliza en campos como geología, geomorfología, ingenierías civil y forestal, arqueología, hidrología y arquitectura, entre otros (Romano, 2004). A pesar de la apertura de esta tecnología en otros campos, los costos económicos que implican su adquisición y uso, siguen siendo altos y son una limitante, especialmente para países en vías de desarrollo, donde su uso práctico enfocado en proyectos para disminuir el riesgo y la vulnerabilidad podría ser clave.

Recientemente, entidades internacionales como el Banco Mundial, han facilitado la implementación de esta tecnología para ayudar a tomar decisiones que reduzcan el riesgo y vulnerabilidad en países con pocos recursos. Para los planes de reconstrucción de Haití después del Terremoto de Puerto Príncipe ( $\mathrm{Mw}$ 7,2; 12/01/2010), se utilizaron imágenes lídar aéreas, para determinar las zonas más susceptibles a tener deslizamientos disparados por exceso de lluvia y movimientos sísmicos (Mora et al., 2012).

En el caso específico de Costa Rica, instituciones académicas de Estados Unidos han realizado investigaciones arqueológicas con lídar desde la década de 1980 (Sheets et al., 1991). Las experiencias más recientes con lídar aéreo en Costa Rica fueron motivadas al igual que en Haití por los efectos de un terremoto; en este caso el de Cinchona (Mw 6,2; 01/08/2009). Los resultados de esta experiencia abrieron la puerta para que instituciones como la Comisión Nacional de Emergencias (CNE) y el Instituto Costarricense de Electricidad (ICE) continuaran haciendo estudios de este tipo en diferentes zonas del país. En el año 2010, el Lanamme-UCR adquirió un escáner lídar terrestre para evaluar deslizamientos, taludes y otros elementos que puedan afectar la red vial nacional. Además, se han explorado aplicaciones en el campo de la arqueología y la restauración patrimonial.

Los principales objetivos del presente trabajo son hacer una síntesis de la evolución que ha tenido la tecnología lídar; explicar su funcionamiento y los tipos de equipos que existen actualmente en Costa Rica; exponer los antecedentes y algunos casos de estudio que se han dado en Costa Rica, y presentar el actual uso que se le da al escáner terrestre con que cuenta el Lanamme-UCR.

\section{EVOLUCIÓN DE LA TECNOLOGÍA LÍDAR}

El origen de esta tecnología se remonta a inicios de la década de 1960, poco después de la invención del láser, específicamente cuando se logró la combinación de imágenes enfocadas con láser y la capacidad del radar de poder medir distancias con base en los tiempos de retorno de sus señales (Flood, 2001).

Como muchas otras tecnologías de uso común en el presente, la tecnología lídar posiblemente tuvo un origen militar, para poder generar 
mapas en zonas de difícil acceso. Esto no está oficialmente documentado, por lo que no existen referencias al respecto. Sin embargo, por su capacidad de poder cartografiar a través de zonas densamente vegetadas, se puede suponer su uso en lugares conflictivos como Vietnam a inicios de los setentas, Nicaragua a inicios de los ochentas, y Colombia en los noventas, entre otros.

Una de las primeras aplicaciones científicas de la tecnología lídar y que eventualmente fue de carácter público, fue el cartografiado de la superficie de la Luna con un altímetro láser durante la misión Apolo 15 en 1971 (NASA, 2009). Posteriormente, sus aplicaciones en la Tierra se extendieron en diferentes campos, especialmente meteorología y la arqueología.

En meteorología, el Centro Nacional de Estudios Atmosféricos de Estados Unidos (NCAR, por acrónimo en inglés) la aplicó principalmente para estudiar fenómenos atmosféricos, como la medición de concentración de gases aerosoles en la atmósfera, medición de nubes, sus estructuras y parámetros como altura, laminación, densidad, propiedades de sus partículas, temperatura, presión, humedad y velocidad del viento en diferentes capas de la atmosfera (Goyer \& Watson, 1963).

En Costa Rica, entre 1984 - 1987, se desarrolló y documentó uno de los primeros casos a nivel mundial de un proyecto arqueológico que contó con soporte de tecnología lídar. Fue parte de una colaboración entre la Universidad de Colorado y la NASA (más adelante se mencionan los principales hallazgos de este estudio).

Para 1994, la tecnología GPS (también de origen militar), ya era completamente operacional e iniciaba a tener acceso al público, al mismo tiempo que se desarrollaban aplicaciones en el campo industrial y académico. A partir de la incorporación y cambio del radar por el GPS de alta precisión a la tecnología lídar, se lograron hacer mediciones extremadamente detalladas en los ejes x y y de coordenadas y asignar una altura respectiva $\mathrm{z}$ (Flood, 2001).

En el siglo XXI se ha acelerado el desarrollo y aplicación del lídar debido, entre otras razones, a que se tornó más práctico, la capacidad y alcance de los equipos mejoró mucho, el tamaño de los instrumentos se ha vuelto más manejable y se logran colocar con mayor facilidad en aviones pequeños y helicópteros. También se han dado grandes avances en tecnologías complementarias como cámaras fotográficas digitales de gran resolución, que incluso pueden captar imágenes en varias bandas espectrales: los equipos de cómputo usados para almacenar la información con alta capacidad de memoria son más pequeños, veloces y económicos, así como el software para el procesado posterior de la información es más amigable, facilitando la expansión y aplicación del lídar. Con estos nuevos equipos se han iniciado trabajos en varios campos y a resolver diferentes problemas, como por ejemplo, una de las primeras experiencias comerciales que se le dio a un equipo lídar aéreo moderno en Estados Unidos, fue la de inspeccionar los corredores de las líneas de alta tensión para determinar las zonas que podrían estar siendo invadidas por vegetación (USDA, 2012), y que ya usa en Costa Rica el Instituto Costarricense de Electricidad (ICE).

\section{Generalidades del funcionamiento de la tecnología lídar}

El principio con el que funciona la tecnología lídar es simple: hace brillar una pequeña luz en una superficie y mide el tiempo en que tarda la luz en regresar a la fuente. Cuando se hace brillar una luz sobre una superficie, lo que uno realmente está observando es la luz reflejada y regresando a la retina del ojo. Como la velocidad de la luz es igual a $3 \times 10^{8} \mathrm{~km} / \mathrm{s}=(\mathrm{V})$, para el ojo humano parece algo instantáneo, aunque no lo es. Por esta razón, el equipo necesario para poder realizar estas mediciones tiene que operar extremadamente rápido. Gracias a los avances tecnológicos y de computación, millones de mediciones se pueden hacer y almacenar en segundos cuando se iluminan diferentes puntos de una superficie con un equipo láser (Campbell \& Wynne, 2011).

La fórmula con la que trabajan estos equipos para medir cuán lejos un fotón de luz ha ido hasta un objeto y regresado (Distancia $=\mathrm{D}$ ), es bastante simple: $\mathrm{D}=(\mathrm{V} \times \mathrm{Tv}) / 2$, donde $\mathrm{Tv}$ es igual al tiempo de vuelo. 
El escáner lídar emite alrededor de 150000 pulsos de rayos láser por segundo hacia el objeto o superficie que se quiere estudiar, un sensor mide el tiempo que le toma a cada pulso en llegar y regresar a la fuente emisora. La luz viaja a una velocidad constante y conocida, por lo que el escáner lídar puede medir la distancia entre él y la superficie con muy buena precisión. Al repetir este proceso en una sucesión rápida, el escáner va generando un mapa completo de la superficie que se está midiendo. Cuando se hace un escaneo de tipo lídar aéreo, el sensor se está moviendo a medida que la aeronave avanza, por lo que otros datos deben ser tomados en cuenta en el cálculo de las mediciones de tiempo y distancia que hace el rayo de luz (latitud, longitud, altura y orientación del instrumento), para determinar la posición del pulso láser en el momento del envío y el retorno. Esta información extra se toma con un receptor GPS de alta precisión, y una unidad de medición inercial o IMU (por sus siglas en inglés Inertial Measurement Unit), los datos tomados son cruciales para guardar la integridad y calidad de la información recopilada. Para un escáner lídar terrestre y estacionario, es suficiente tener el dato de la ubicación del escáner tomada con un GPS en cada sitio donde se hagan las mediciones (Campbell \& Wynne, 2011).

\section{Métodos de detección}

Existen dos tipos de métodos de detección lídar. Uno utiliza energía directa (detección incoherente), mientras que el otro utiliza energía indirecta (detección coherente). Los sistemas coherentes son recomendados cuando se combinan con tecnología doppler o medidas de fase sensitiva, y generalmente utilizan detección óptica de tipo heterodino que genera una nueva frecuencia mediante la mezcla de dos o más señales en un dispositivo no lineal. Esto permite operar en un rango de poder más bajo, pero tiene el costo de un transceptor con requerimientos más complejos. Para ambos existen dos tipos de sistemas de emisión de pulso: sistemas de micropulso, y de alta energía o de medición de fase.
Los de micropulsos utilizan un proceso para la medición de la distancia entre el sensor y el terreno que se lleva a cabo mediante la medición del tiempo que tarda un pulso desde que es emitido hasta que es recibido. Los rayos láser que se utilizan son de menor poder y son clasificados como seguros para los ojos humanos, permitiendo su utilización con pocas medidas de seguridad.

Los de alta energía o medición de fase utilizan un emisor o escáner que emite un haz láser continuo. Cuando recibe la señal reflejada, mide la diferencia de fase entre la emitida y la reflejada, posteriormente se resuelve el número de longitud de ondas enteras que han recorrido, para medir distancias. Son comúnmente utilizados en estudios atmosféricos y sí requieren de precauciones para los ojos al ser utilizados.

Los equipos lídar pueden ser transportados mientras toman datos, por lo que se pueden montar en aeronaves o sobre automóviles. Cuando se van a realizar trabajos de forma estática se montan sobre un trípode, y usualmente se hacen mediciones desde varios sitios. A continuación, se describen los principales aspectos de estos equipos y sus utilidades.

\section{Lídar aéreo}

Varios autores han trabajado sobre el funcionamiento de la tecnología lídar cuando es aerotransportado (Hill et al., 2000; Hyyppä et al., 2009 y Campbell \& Wynne, 2011), y aquí se resumen las principales ideas de estos trabajos. Un sistema de lídar aéreo está constituido por cinco instrumentos básicos, y se pueden montar sobre un avión o un helicóptero: un sensor o escáner lídar (usualmente de micropulsos), un receptor GPS de alta precisión en la aeronave y otro en una estación terrestre, una unidad de medición inercial (IMU), una cámara digital para fotografías aéreas de gran/mediano formato, y una computadora con dispositivos de almacenamiento de información de alta capacidad (Fig. 1).

En un sistema lídar aéreo, se emite un pulso láser hacia un espejo que lo proyecta desde una plataforma aérea usualmente adherida a una parte 


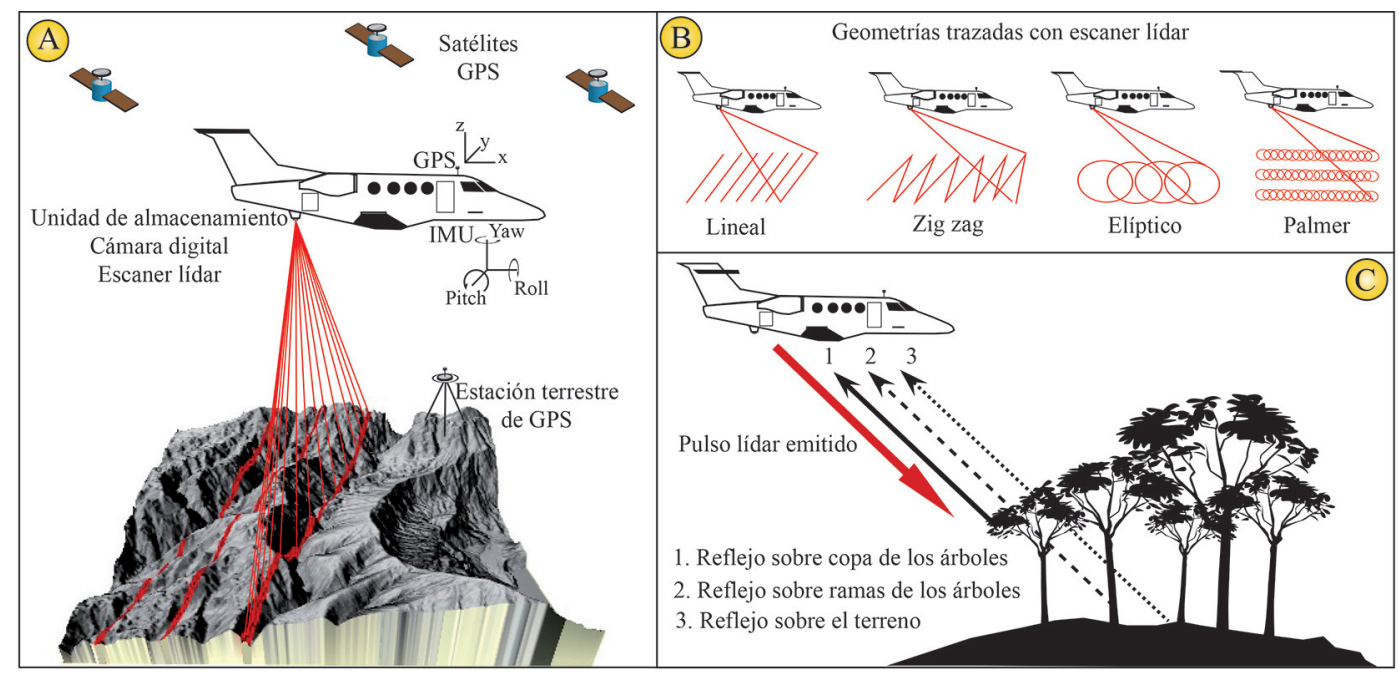

Fig. 1: A.) Esquema explicativo de funcionamiento de un equipo básico de lídar aéreo transportado generado con imágenes lídar del sector este del cráter del volcán Poás. B.) Geometrías que se pueden trazar con el escáner lídar durante un barrido. C) Esquema sobre el orden de retorno de un pulso lídar emitido desde un avión.

baja del avión o del helicóptero. Mientras la aeronave sobrevuela el área de estudio en una ruta predeterminada, el rayo láser realiza un escaneo que puede seguir al menos cuatro geometrías: lineal, o de lado a lado, zigzag, elíptica, o Palmer (Fig. 1). Sin importar la geometría utilizada para el barrido de datos, el patrón de puntos de retorno es interpolado después de la adquisición de datos, para generar un arreglo regular que formará la imagen lídar.

El equipo lídar mide el intervalo entre el pulso láser cuando deja la plataforma de la nave, se topa un objeto y se refleja, y luego su retorno al sensor lídar. Durante este proceso el escáner pasa midiendo entre 20000 y 100000 puntos por segundo, que son almacenados en la memoria de la computadora, y a toda esta información se le conoce como nube de puntos. Una característica distintiva de los retornos en zonas con vegetación es que estos se pueden producir a diferentes niveles, siendo posible que el último retorno se produzca al nivel del terreno (Fig. 1). La nube de puntos puede ser manipulada para que solamente utilice los puntos del último retorno y así generar un MED de la topografía sin vegetación. La misma teoría es aplicada con infraestructuras, como puentes, edificios, casas, automóviles, etc.
Los sistemas lídar aéreos generalmente utilizan un láser de tipo diodo YAG (por acrónimo en inglés, Yttrium Aluminium Garnet), que usa cristales de una variedad de granate (óxido de itrio y aluminio: $\mathrm{Y}_{3} \mathrm{Al}_{5} \mathrm{O}_{12}$ ), para la amplificación de su radiación de longitud de onda característica de $1064 \mathrm{~nm}$ en el infrarrojo.

Los sistemas lídar aéreos con batimetría usan el mismo principio, pero presentan un láser tipo doble diodo YAG con una longitud de onda de $532 \mathrm{~nm}$, que le permite penetrar el agua con mucho menos atenuación que el sistema normal. Este tipo de escáner con capacidad de levantar batimetría es utilizado para cartografía litoral de zonas poco profundas $(<20 \mathrm{~m})$, como esteros, arrecifes, zonas portuarias, perfiles de río y zonas de inundación.

Con la información almacenada en la computadora, se realiza un trabajo posterior en tierra en el que se mide el intervalo de tiempo lídar entre el pulso emitido y el pulso recibido convirtiéndolo en distancia y corrigiéndolo con el receptor GPS a bordo, la IMU y estaciones GPS fijas en tierra. La cantidad de información que genera un sensor lídar en un proyecto puede llegar a ser de millones de puntos que equivalen a varios terabytes. 
La IMU se utiliza para determinar los ángulos de navegación, ángulo de alabeo, dirección y la altitud (roll, pitch y yaw) de la nave en el momento en que se hace el escaneo lídar, así como movimientos verticales y horizontales de la nave en vuelo (Fig. 1). Con la información del GPS y la unidad IMU, se calcula la geometría del rayo láser de salida relativa con las coordenadas de superficie de la Tierra.

La información lídar generada inicialmente puede ser mejorada con trabajo adicional y depurado de forma manual o automática. Tratamientos más complejos utilizan señales de retornos múltiples de cada pulso láser. Mediante la evaluación de los diferentes tiempos de retorno en las señales múltiples, se pueden diferenciar edificios y otras estructuras, vegetación y la superficie del terreno. Esta técnica se utiliza para generar MED en los que se puede elegir cuáles elementos se pueden visualizar, tales como vegetación, edificios, estructuras y topografía del terreno.

Posteriormente, con las fotografías aéreas y el MED generado con la información lídar, se pueden crear modelos y visualizaciones que facilitan la compresión de un sitio de estudio y poder resolver problemas.

Para generar imágenes lídar aéreas de alta resolución, se requiere de un barrido detallado y de varias pasadas del equipo. Usualmente, para este tipo de trabajos, se utiliza el escáner montado en un helicóptero, ya que esta aeronave tiene la capacidad de volar a bajas velocidades y maniobrar en lugares de difícil acceso. Este tipo de captura de información es utilizado en proyectos donde se requiere hacer la cartografía en detalle en sitios tipo corredor y sin interrumpir sus operaciones. Algunos ejemplos de este tipo de proyectos son acueductos, oleoductos, líneas de transmisión, carreteras, y líneas de ferrocarril, entre otros.

En proyectos donde el área de interés es extensa, usualmente se usa el escáner lídar montado sobre un avión o avioneta, que es más veloz y su maniobrabilidad es reducida, por lo que la resolución del un escaneo lídar desde ella va a ser menor que el realizado desde un helicóptero. Sin embargo, tiene como ventaja que la captura de las imágenes es más rápida y eficiente.

\section{Resolución de imágenes de lídar aéreo}

Un escáner lídar aerotransportado puede trabajar con distintas resoluciones. Esta se mide en puntos $/ \mathrm{m}^{2}$ y depende de varios factores: velocidad de la aeronave, ancho del barrido, número de pasadas y traslapes de líneas de barrido. La densidad de puntos/m2 requerida para un trabajo depende del uso posterior que se le vaya a dar a la información generada.

Sin importar la resolución utilizada para un proyecto, las imágenes lídar siempre deberían estar acompañadas de ortofotografías de muy alta resolución (entre 10 y $15 \mathrm{~cm}$ ), tomadas con cámaras digitales de mediano y gran formato. Además, deberían estar sin presencia de nubosidad en casi un $99 \%$ del área de estudio. Estas fotografías permiten interpretar con mayor facilidad la realidad de la zona, sirviendo de marco visual y manto de superposición sobre los productos vectoriales de diseño y los modelos de elevación digital.

Una densidad baja (1 - 2 puntos $/ \mathrm{m}^{2}$ ) se logra obtener con una única pasada de la aeronave y para un ancho de barrido de hasta $1350 \mathrm{~m}$. Se puede realizar en un avión y por su velocidad disminuye el tiempo de toma de datos. Esta resolución es recomendable para proyectos de grandes extensiones a lo largo y a lo ancho (>500 $\left.\mathrm{km}^{2}\right)$, conveniente para zonas que tengan poca infraestructura y que requieran poco detalle. También es recomendable para zonas donde anteriormente se ha dificultado el mapeo y la generación de información topográfica desde tierra por el difícil acceso.

Con los productos generados con esta densidad de puntos, en los MED se pueden apreciar carreteras, caminos secundarios, ríos, quebradas, deslizamientos grandes ( $>5 \mathrm{~m}$ de longitud en la corona), y diferencias entre tipos de vegetación (Nelson et al., 1988; Nilsson, 1996), entre otras cosas (Fig. 2). También se pueden generar perfiles topográficos y mapas topográficos con curvas de nivel a $1 \mathrm{~m}$ de diferencia.

La densidad media $\left(3-4\right.$ puntos $\left./ \mathrm{m}^{2}\right)$ se puede conseguir con una sola pasada de la aeronave, en un ancho de banda de barrido de hasta $800 \mathrm{~m}$. Se puede realizar con un avión para mejorar el 

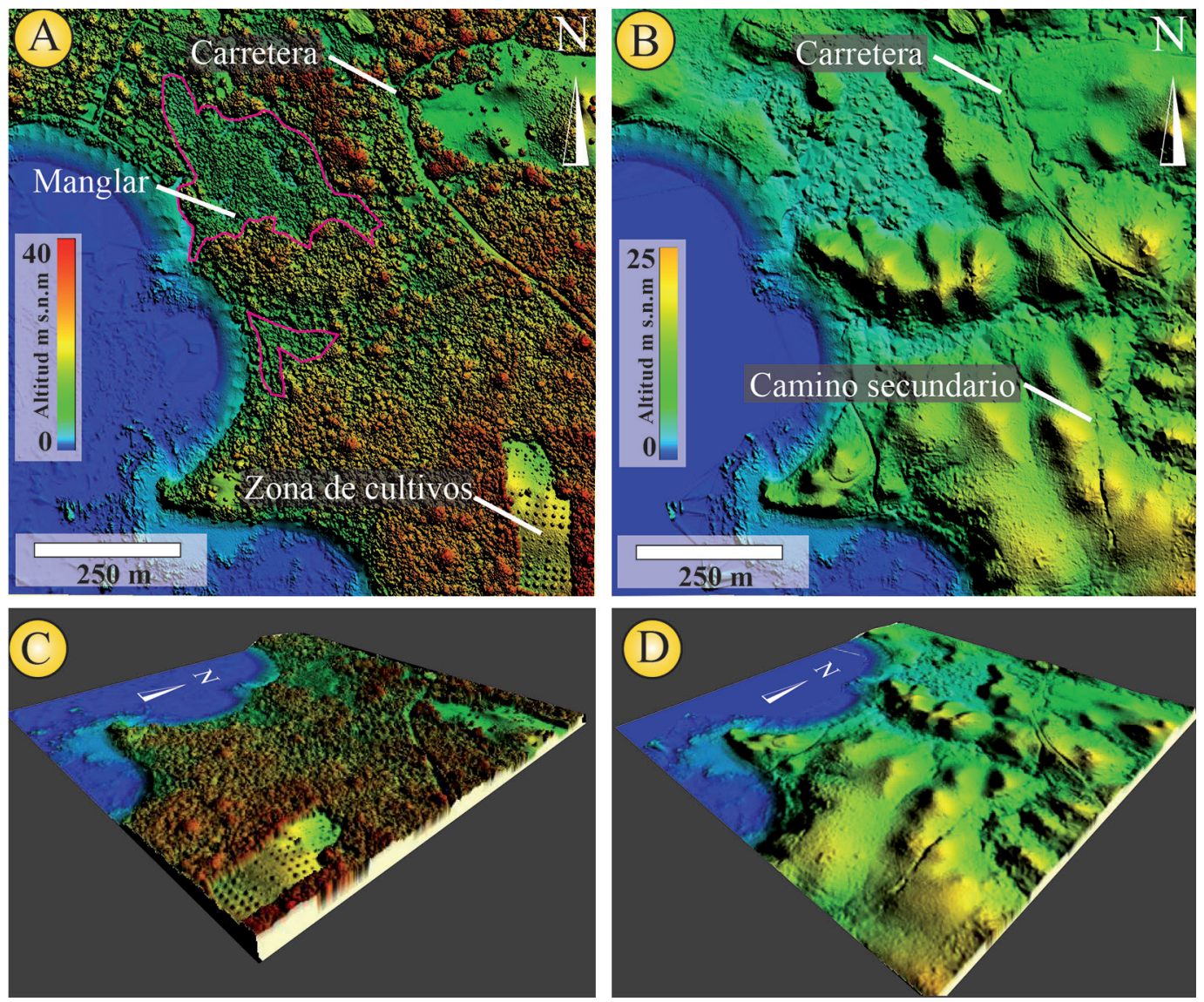

Fig. 2: MED generados con una resolución de 1 punto por $\mathrm{m}^{2}$ en la costa pacífica de Costa Rica, A) Con vegetación, en el que es posible distinguir una carretera en el sector noreste. B) Sin vegetación, se puede observar un camino secundario que comunica una zona de cultivos con la carretera en el sector noreste. Hay una diferencia de altitud de casi $15 \mathrm{~m}$ entre los MED con vegetación y sin vegetación, debido a la altura que pueden alcanzar los árboles en las colinas y la vegetación en la zona de manglar. Con esta herramienta y conocimiento de la flora del lugar, se podrían hacer inventarios forestales. C) y D) Vistas ortográficas de los MED con y sin vegetación. Imágenes generadas con información cortesía de AeroDiva.

tiempo de captura de datos, pero también es posible que se pueda obtener desde un helicóptero y así mejorar la resolución en los traslapes entre las bandas. Esta resolución es recomendable para proyectos de tipo corredor, como tuberías, oleoductos de más de 2 metros de diámetro, carreteras, zonas de fallas tectónicas, deslizamientos y líneas de ferrocarril. Sin embargo, no es suficiente para proyectos rectilíneos como las líneas de transmisión. En Costa Rica se ha utilizado esta resolución en proyectos como el de la Ruta Nacional $N^{\circ} 32$, Carretera Braulio Carrillo (Fig. 3).
Con los productos generados con esta densidad de puntos, en los MED se pueden apreciar carreteras, ríos, quebradas, edificaciones y se pueden distinguir varios tipos de vegetación.

La densidad media - alta (6 - 8 puntos- $\left.\mathrm{m}^{2}\right)$ requiere de al menos dos pasadas de la aeronave, para un ancho de banda de barrido de $750 \mathrm{~m}$. Es preferible que se realice con el escáner lídar montado sobre un helicóptero, debido a que se requieren velocidades más bajas para tomar los datos y así mejorar la resolución en los traslapes entre las bandas. Esta resolución es recomendable para proyectos 
de tipo corredor que requieran mayor detalle que los vistos anteriormente, como represas, tuberías, oleoductos, carreteras, zonas de fallas tectónicas, coronas de deslizamientos, grietas y líneas de ferrocarril (se pueden apreciar carreteras, cunetas, ríos, quebradas, edificaciones, automóviles, torres de alta tensión, y se pueden distinguir varios tipos de vegetación, incluyendo arbustos). Esta resolución permite trabajos limitados en proyectos rectilíneos como las líneas de transmisión, debido a que se pueden reconocer torres de alta tensión y estructuras en subestaciones, pero aún no es suficiente para poder observar los cables eléctricos, aunque posteriormente esta información se puede correlacionar con barridos de muy alta resolución realizados con un escáner en tierra. En Costa Rica se ha utilizado esta resolución para zonas donde el ICE tiene subestaciones (Fig. 4).

Para poder obtener una resolución de densidad alta (15-20 puntos $\left./ \mathrm{m}^{2}\right)$, se ocupan hasta tres pasadas paralelas y el ancho de banda se reduce hasta los $350 \mathrm{~m}$. Además, requiere de pasadas perpendiculares para tener aún más traslapes y poder obtener un alto grado de detalle. El escáner lídar tiene que ser montado sobre un helicóptero, ya que es necesario que las pasadas sean a baja velocidad, lo que alarga el tiempo de toma de datos. Este tipo de barridos es recomendable para zonas urbanas. Se pueden identificar diferencias de altura entre las aceras y las calles, peralte de las vías, detalles de los caños, automóviles, edificios con detalles centimétricos y diferentes tipos de vegetación (Fig. 5).

Los valores de las resoluciones presentadas anteriormente, no son definitivas y podrían servir como primeras referencias, ya que cada trazado es diferente. Para determinar la resolución de un proyecto también hay que tomar en cuenta el relieve de la zona y la geometría del proyecto. La configuración de los sensores se tiene que ajustar al trazado de vuelo definido. Cuando el relieve no es plano, las pasadas tienen menos ancho y cuando hay muchas curvas, también hay que tener en cuenta que el vuelo se tiene que cortar mucho; esto se puede solucionar con más pasadas paralelas para cubrir el área de interés por la sinuosidad.

\section{Lídar terrestre}

Un sistema de lídar terrestre estacionario funciona muy similar al aéreo. Sin embargo, existen algunas diferencias importantes, como que no requiere una unidad IMU y en algunos casos se puede prescindir de un GPS. La información recopilada durante el escaneo también se puede enlazar con fotografías digitales que se toman posteriormente al barrido láser, aunque usualmente no son de alta resolución, ya que se utilizan solamente para dar texturas a las nubes de puntos. El láser puede ser reflejado por objetos como fachadas de edificios, postes de electricidad, vegetación, carros y hasta personas. Sobre la superficie del terreno puede registrar cárcavas, reptación y grietas de tan solo unos $\mathrm{cm}$ de ancho. Todos los pulsos de retorno registrados son almacenados en la memoria del mismo escáner y se calcula la distancia entre el instrumento y el objeto donde se reflejó el rayo láser. Usando principios de física y óptica, el escáner puede obtener la posición de cada punto a partir del haz refractado, la cual es almacenada como una coordenada $\mathrm{x}-\mathrm{y}-\mathrm{z}$. Gracias a varios servomotores, este conjunto emisor / receptor gira sobre su eje horizontal, mientras que el escáner gira sobre su eje vertical, con lo que le da capacidad de realizar un levantamiento de $360^{\circ}$ de horizonte, con una apertura de bóveda de $270^{\circ}$ (la base del equipo, donde se acopla el trípode, genera un cono ciego inmediatamente debajo del escáner, Fig. 6). En teoría, es posible escanear a distancias de hasta 300 metros, pero para efectos de obtener la mayor información del objeto levantado, se trata de limitar a 50 metros. Lo anterior permite obtener un error máximo de ubicación de puntos de $3 \mathrm{~mm}$, el cual puede reducirse a $<1$ $\mathrm{mm}$ si se aplican procedimientos de topografía de precisión, rutinas que se encuentran incluidas en el software de la unidad.

Debido a que una estructura como un edificio no puede levantarse usando sólo una posición (se generan sombras en aquellas partes que no tienen línea de vista al escáner), es necesario mover el equipo a nuevas posiciones, para lo cual se cuentan con una serie de objetivos topográficos cuya 
finalidad es la de amarrar las estaciones entre sí. Cuando se termina un levantamiento, en el disco duro interno del escáner se almacena una nube de puntos con la totalidad de las coordenadas $\mathrm{x}-\mathrm{y}$ - z, así como las posiciones relativas de cada objetivo. Además, la unidad cuenta con una cámara fotográfica digital de baja resolución, cuya finalidad es la de obtener el color verdadero de cada objeto que fue levantado.

A la nube de puntos y los datos asociados se les realiza un trabajo de procesamiento utilizando un software propietario instalado en una computadora con alta capacidad de memoria, imagen y video. Con este equipo se crea el modelo tridimensional, que dependiendo de las condiciones de luminosidad, textura y cantidad de sitios de escaneo realizados, puede tener entre 5 - > 50 millones de puntos. Lo anterior pone en evidencia las únicas debilidades del equipo: el requerimiento de utilizar un programa especializado de proceso de datos, el cual es único para el escáner y que requiere de un entrenamiento especial, y la necesidad de utilizar un equipo de cómputo de gran desempeño gráfico y de procesador. Con el modelo tridimensional creado, es posible realizar un recorrido virtual de la estructura, obteniendo a su vez distancias, alturas, pendientes y volúmenes, con un alto grado de precisión. Además, a partir de este modelo se pueden crear superficies, figuras sólidas y modelos de elevación que pueden ser utilizados en programas tipo CAD o en Sistemas de Información Geográfica (SIG).

Dependiendo del tamaño del objeto o estructura a escanear, su accesibilidad y de la línea de vista que se pueda obtener de los alrededores, es que se planifica con antelación un esquema de levantamiento, con el número de estaciones necesarias y la cantidad de puntos de amarre requeridos. Como dato, en una jornada continua de 8 horas (tiempo aproximado que rinden las baterías del escáner), es posible levantar de 12 a 15 estaciones "amarradas" con sus respectivos objetivos. Montar el modelo en la oficina y realizar su limpieza, proceso en el cual elementos que no son necesarios son eliminados del modelo obtenido, tarda aproximadamente el doble del tiempo.
Si bien es posible realizar un levantamiento bajo cualquier condición de luz (natural, artificial, o incluso en condiciones nocturnas), no se recomienda hacerlo cuando llueve, esto porque cada gota de agua refleja y refracta los haces de láser, con lo cual el equipo registra su posición. El modelo que se obtiene, refleja lo anterior presentando una especie de "neblina": gran cantidad de puntos distribuidos aleatoriamente entre el sitio de escaneo, y el objeto levantado, lo cual agrega tiempo de post proceso y resta mucha precisión al modelo

\section{ANTECEDENTES DE USO DE TECNOLOGÍA LÍDAR EN COSTA RICA}

En esta sección se mencionan cuatro ejemplos de uso de imágenes lídar en Costa Rica. Dos corresponden a lídar aéreos, relacionados con temas de arqueología alrededor del volcán Arenal y mapeo geológico en el sector norte del volcán Poás. Los otros dos ejemplos corresponden con casos de estudio de lídar terrestre realizados por el Lanamme-UCR sobre un deslizamiento en la Ruta Nacional $\mathrm{N}^{\circ} 1$ y la esfera precolombina que se encuentra en la Facultad de Agronomía de la Universidad de Costa Rica.

\section{Casos de lídar aéreo}

\section{Asentamientos y trillos precolombinos en los alrededores del volcán Arenal (1984-1987)}

Entre los años 1984 y 1987, la Universidad de Colorado, la NASA y el Instituto Geográfico Nacional llevaron a cabo en el noroeste de Costa Rica un estudio integral llamado "Proyecto Prehistórico Arenal". Este proyecto combinó resultados de cuatro diferentes campos (arqueología, botánica, vulcanología y sensores remotos) con el objetivo de datar y establecer marcos culturales y de actividad volcánica en un ambiente tropical para entender mejor la evolución y comportamiento de los asentamientos precolombinos, su 

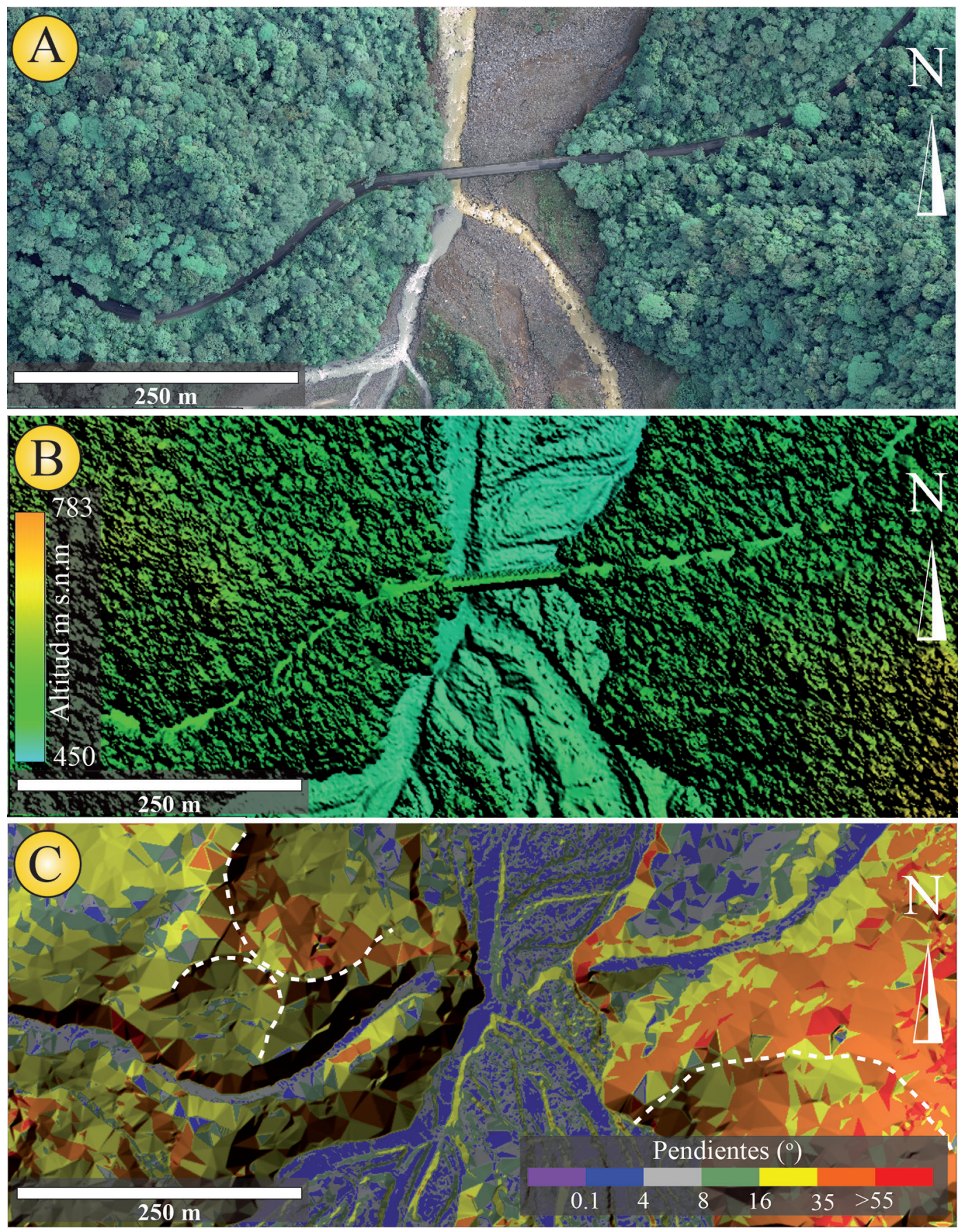

Fig. 3: A) Fotografía aérea ortorrectificada de la zona del río Sucio sobre la Ruta Nacional $\mathrm{N}^{\circ} 32$. B) MED con vegetación generado con una resolución de 4 puntos $/ \mathrm{m}^{2}$ C) MED sin vegetación ni estructuras con superposición de las pendientes. Nótese cómo el puente sobre el río Sucio ha sido removido, y con los cambios de pendiente en las laderas se pueden observar varias morfologías de herradura que con la vegetación no era posible identificar. Imágenes generadas con información cortesía de AeroDiva. 

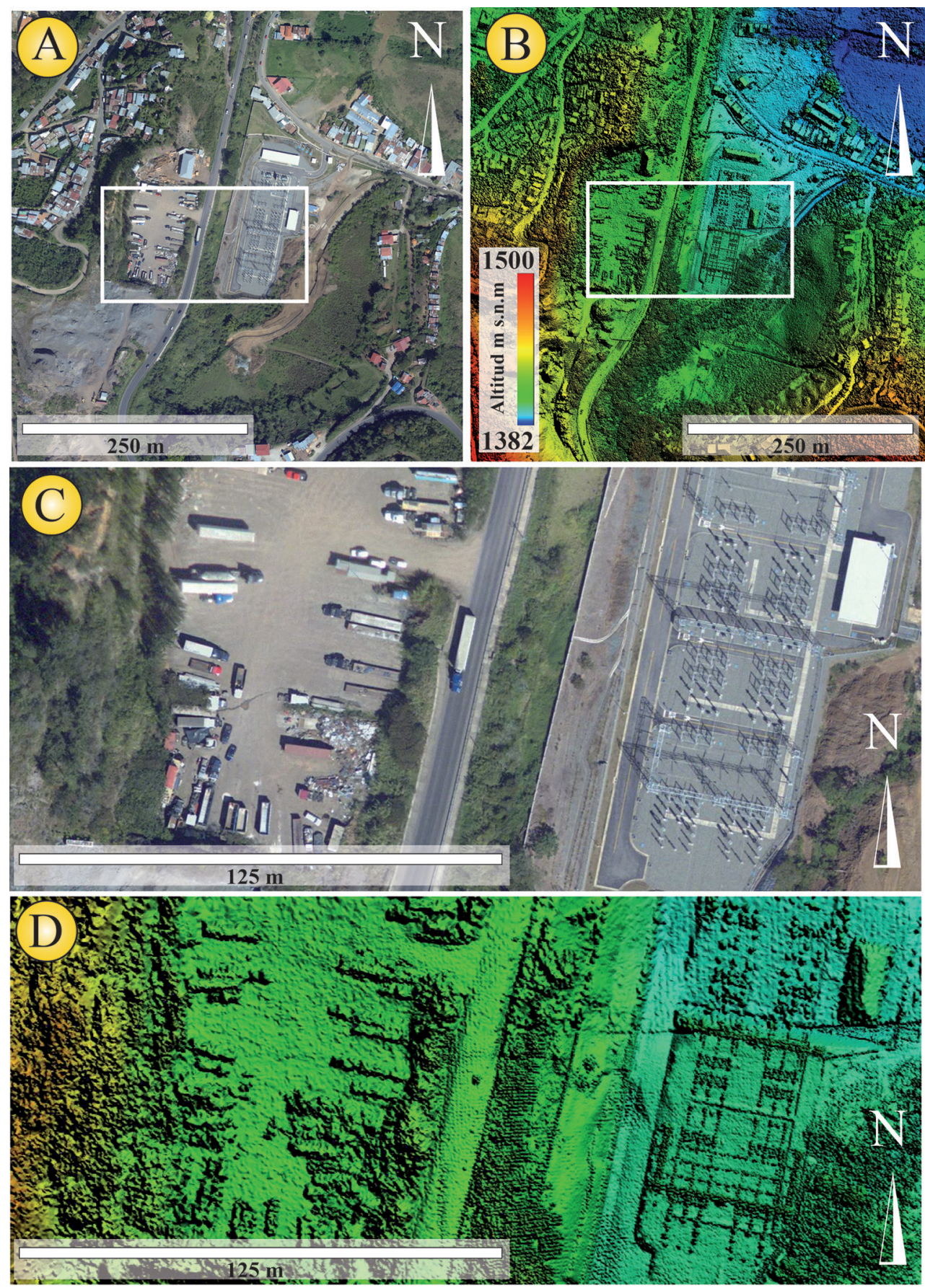

Fig. 4: A) Fotografía aérea ortorectificada de la zona de El Guarco, Cartago. B) Modelo de elevación digital con vegetación e infraestructura. C) Detalle del recuadro de la figura A, donde se observa a la derecha una subestación eléctrica. D) Detalle del recuadro de figura $\mathrm{B}$, en el cual se observan los automóviles estacionados y estructuras que no son totalmente sólidas, como las torres eléctricas de la subestación. Imágenes generadas con información cortesía de AeroDiva. 

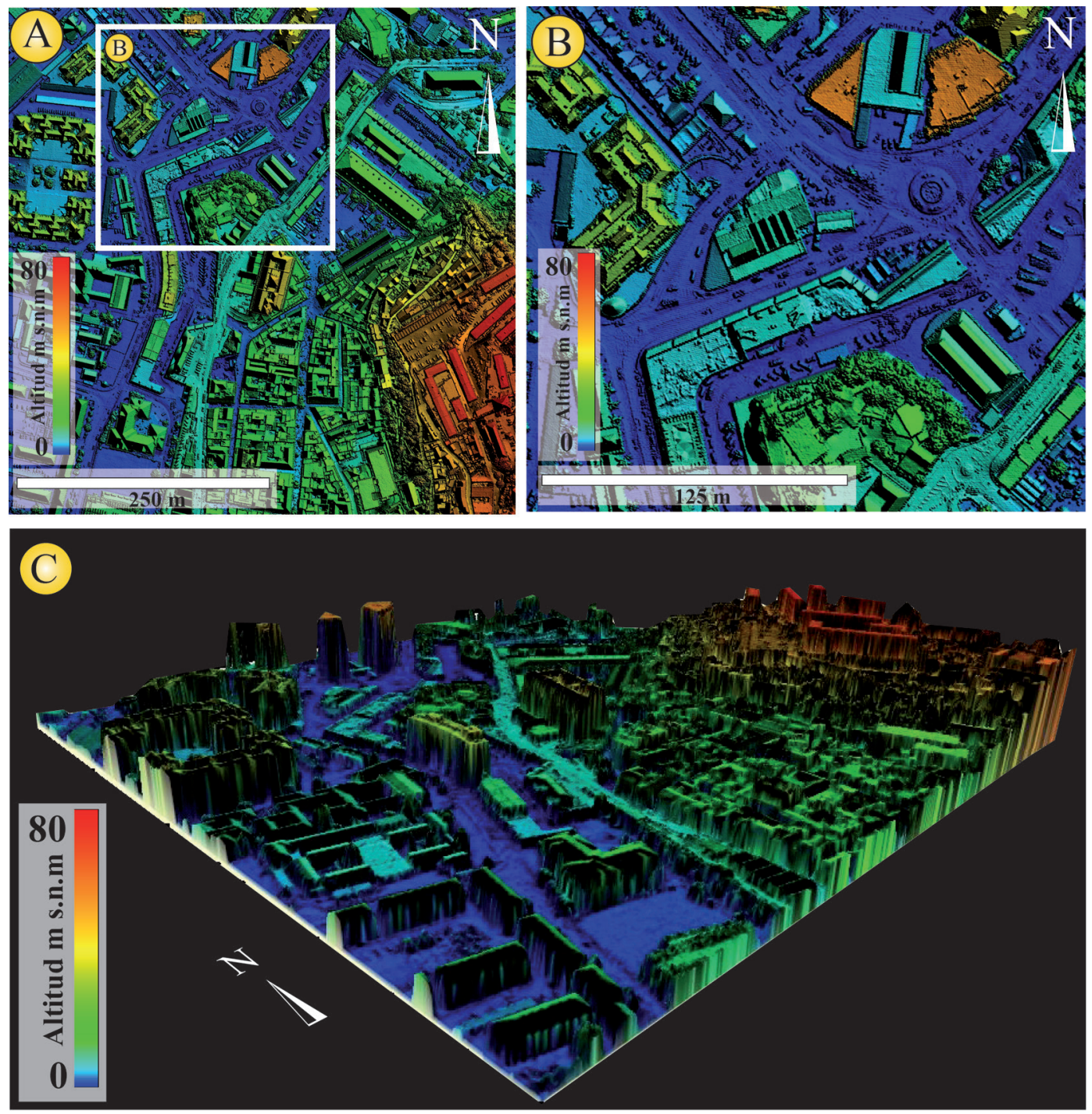

Fig. 5: A). MED generado con una nube de 20 puntos por $\mathrm{m}^{2}$ en promedio. B). Detalle de sector marcado con un cuadro blanco. C). Vista oblicua del MED. Imágenes generadas con información cortesía de AeroDiva.

subsistencia y su desarrollo tecnológico alrededor de un volcán activo. Este proyecto fue pionero a nivel mundial debido a que se utilizó por primera vez y con éxito, tecnología lídar con fines arqueológicos. Además de las imágenes lídar, para ese estudio también se utilizaron imágenes infrarrojas y tecnología de radar para medir distancias.

Uno de los resultados más importantes y claves de este proyecto ligado con la utilización de tecnología lídar, fue que se logró detectar numerosas anomalías lineales en la topografía, que posteriormente fueron confirmadas en el campo como trillos y senderos precolombinos, los cuales fueron realizados y utilizados por los habitantes de la zona del volcán Arenal hace más de 2000 años (Sheets et al., 1991). Se puede decir entonces que estas zonas de paso en medio del bosque lluvioso, fueron varios de los primeros sistemas de transporte y comunicación de los antiguos habitantes de Costa Rica. 


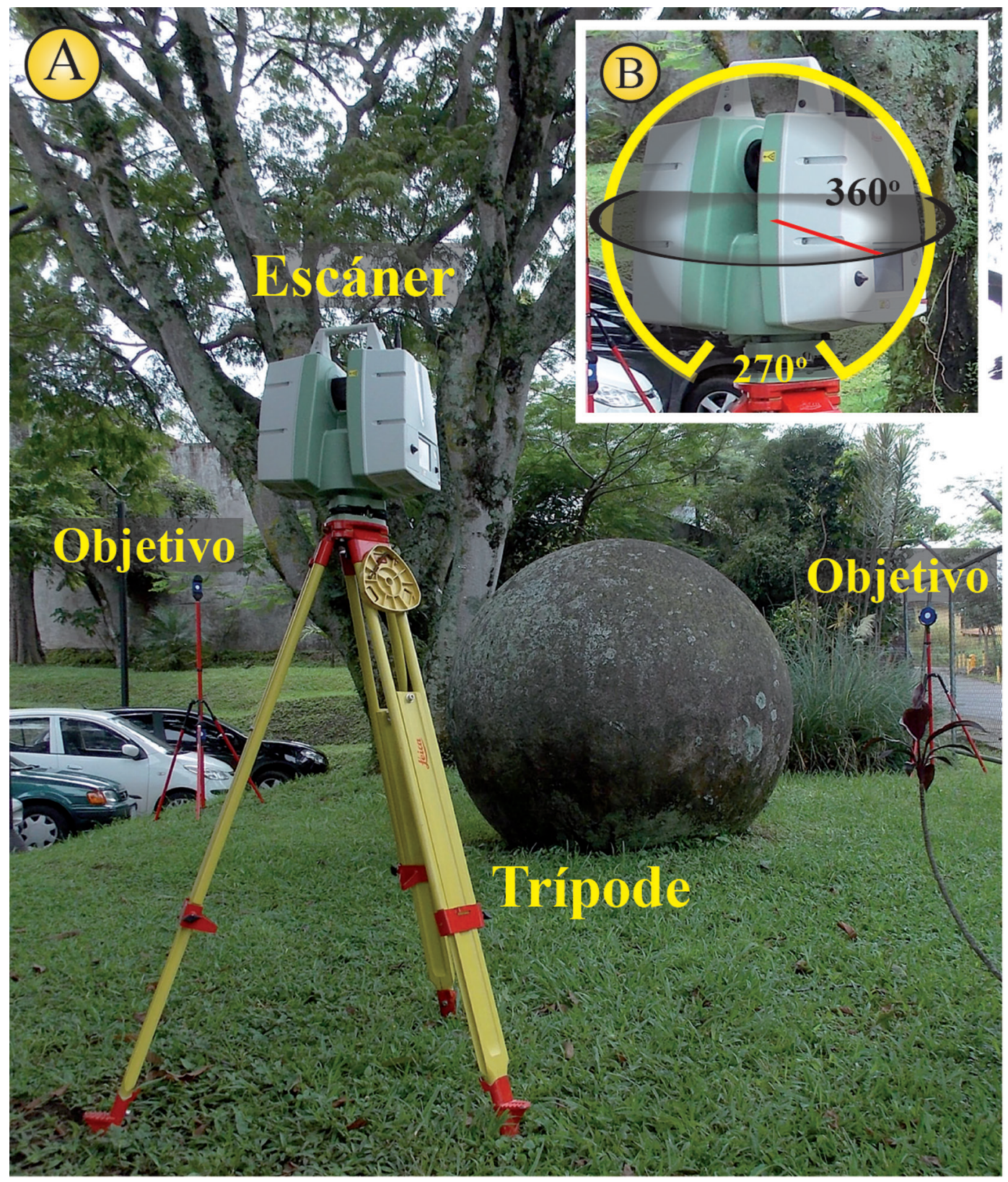

Fig. 6: A). Escáner lídar terrestre con dos objetivos alrededor de una esfera precolombina en la Facultad de Ciencias Agroalimentarias de la Universidad de Costa Rica. B. Detalle de apertura de medición del escáner lídar. Véase el texto más adelante para detalles.

Las anomalías lineales se detectaron en las imágenes lídar como irregularidades angostas ( $\sim 1 \mathrm{~m}$ de ancho) y alargadas (algunas de varios kilómetros) en sitios donde la morfología era suave debido a la cobertura de tefras y cenizas y cubiertas por vegetación (Sheets \& Sever, 1988). Los estudios de campo realizados sobre los senderos revelaron evidencias de asentamientos 
hacia 2000 años antes del presente (A.P.) en las inmediaciones del volcán Arenal, que poseían un sistema complejo y elaborado diseño de rutas de comunicación y transporte. Se logró demostrar que en los asentamientos se presentó una tendencia a que existieran mayores distancias entre las villas y los cementerios. Además, se comprobó que distintos senderos encontrados bajo la densa vegetación comunicaban con sitios donde se extraían recursos como agua, materiales de construcción como lajas y con los campos de siembra de maíz (Sheets et al., 1991).

Estudio de maares Laguna Hule, Pata de Gallo y Río Cuarto (Volcán Poás, 2010)

Con las imágenes lídar tomadas en el volcán Poás en el año 2009, se realizaron estudios geológicos y geomorfológicos en detalle de los cráteres de explosión (maares) de Río Cuarto, Pata de Gallo y Laguna Hule. Se midieron largo, ancho, alturas máximas y mínimas de los bordes de los cráteres, áreas, y perímetros entre otros, con una resolución nunca antes observada en un territorio volcánico de América Central. Algunos de los datos obtenidos fueron publicados por Alvarado et al. (2011) en un estudio que también incluyó geoquímica y distribución de los productos generados por estos cráteres explosivos (Cuadro 1).

Las imágenes lídar con las que se trabajó en ese proyecto fueron tomadas con el equipo montado sobre un avión en abril del 2009, por parte de la compañía STEREOCARTO SA. Para esto utilizaron un sistema ALS50-II Leica con frecuencia de pulso de hasta $300000 \mathrm{~Hz}$ y una cámara fotogramétrica digital de mediano formato Leica RCD 105, de 39 Mega pixeles. La resolución de las imágenes lídar obtenidas es de hasta 3 puntos/ $\mathrm{m}^{2}$ lo cual fue suficiente para crear un MED con una resolución de $50 \mathrm{~cm}$ en los ejes $\mathrm{x} y \mathrm{y}$, y de 15 $\mathrm{cm}$ en el eje z. La diferencia de altitud entre las imágenes y la registrada en los objetivos de los mapas topográficos es menor de $11 \mathrm{~cm}$.

Uno de los hallazgos más importantes del trabajo de Alvarado et al. (2011) y que tiene relación directa con la utilización de tecnología lídar, fue que en el caso del maar de Laguna de
Hule, gracias a la capacidad de poder eliminar la vegetación del MED se descubrió que existen dos conos piroclásticos intra-maáricos y no solamente uno, como se pensaba y observaba anteriormente. Uno de los conos al formarse destruyó parte del cono más viejo que solo pudo conservar un sector. También se pudo determinar con claridad la existencia de tres diferentes coladas de lava, donde al menos una de ellas parece que tuvo origen en el primer cono y las dos restantes en el segundo cono.

Posteriormente al trabajo de Alvarado et, al. (2011), se comprobó con trabajo de campo la existencia de al menos dos de los contactos geológicos entre los conos intra-maáricos y otro más entre el campo de coladas de lava 1 y 3 . Estos, en algunos casos, se presentaron cubiertos con material piroclástico como escorias de coloración rojiza.

Aquí se presenta una interpretación geológica sin la cubierta de materiales piroclásticos y cenizas de la zona de Laguna Hule (basada en los datos de Ruiz et al., 2010), sobre el modelo de elevación digital generado a partir de imágenes lídar (Fig. 7). Además se presenta un perfil geológico de cómo se especula que podría ser el interior de este cráter explosivo basados en factores que posiblemente controlaron la arquitectura de sus facies internas basados en Kurszlaukis \& Fulop (2013) (Fig. 8).

\section{Trabajos realizados con lídar terrestre}

La Unidad de Gestión y Evaluación de la Red Vial Nacional del PITRA - Lanamme-UCR adquirió en julio del 2012 un escáner láser, con el objeto de realizar levantamientos de taludes y terraplenes susceptibles a problemas de deslizamiento, en rutas nacionales. Gracias a la tecnología de punta que presenta este instrumento, los modelos creados son más precisos y se obtienen en mucho menos tiempo, permitiendo mejorar las evaluaciones de tramos críticos de vías, ante amenazas naturales.

El equipo adquirido es un escáner láser Leica C10, que es un equipo de segunda generación, en el sentido que presenta baterías internas de alta 


\section{Cuadro 1}

Resumen de datos paramétricos obtenidos a partir de imágenes lídar en los cráteres de explosión al norte del volcán Poás (reformado a partir de Alvarado et al., 2011)

\begin{tabular}{cccc}
\hline Maar & Laguna Hule & Pata de Gallo & Río Cuarto \\
\hline Forma & Subcircular & Circular & Circular \\
Eje mayor $(\mathrm{km})$ & 2,3 & 0,4 & 847 \\
Eje menor $(\mathrm{km})$ & 1,8 & 0,38 & 758 \\
Área total $\left(\mathrm{km}^{2}\right)$ & 3,5 & 0,14 & 0,45 \\
Perímetro total $(\mathrm{km})$ & 7,2 & 1,32 & $2,51 \mathrm{z}$ \\
Altitud máxima (m s.n.m.) & 978 & 990 & 412 \\
Altitud mínima (m s.n.m.) & 777 & 889 & 362 \\
Pendientes de bordes internos $\left(^{\circ}\right)$ & $27-76$ & $25-79$ & $10-70$ \\
\hline
\end{tabular}

capacidad, y que permiten que el conjunto tenga portabilidad verdadera. Físicamente, tiene el tamaño aproximado de una estación topográfica total, y un peso menor a los $20 \mathrm{~kg}$, lo que permite montarlo en un trípode normal (véase la Fig. 6). Presenta un conjunto emisor/receptor láser que es capaz de enviar 50000 haces de luz por segundo; sin embargo, según el tipo de material superficial del objeto levantado, la tasa de retorno al receptor ronda entre menos de $1 \%$, hasta $5 \%$ de los haces emitidos. El escáner presenta cuatro niveles de resolución.

Nivel bajo: al escanear un objeto a $50 \mathrm{~m}$ de distancia, se obtiene de él una nube de puntos que en promedio, están separados aproximadamente 5 $\mathrm{cm}$. Es el modo de escaneo más rápido (en promedio, menos de 10 minutos por estación), recomendado para realizar levantamientos donde el nivel de información que se requiere del objeto o estructura no es muy alto.

Nivel medio: trabajando a una distancia de $50 \mathrm{~m}$, la separación de los puntos del modelo obtenido se reduce a $2 \mathrm{~cm}$. Esta es la configuración usada para la mayor parte de escaneos realizados, dado que brinda un buen balance entre información y tiempo en campo (20 minutos en promedio por estación).

Nivel alto: la separación se reduce a $1 \mathrm{~cm}$ aproximadamente, y se recomienda para levantar objetos con mucho detalle, como estatuas. El tiempo por estación de escaneo es de $40 \mathrm{mi}$ nutos aproximadamente.
Nivel muy alto: la separación es de menos de $5 \mathrm{~mm}$, útil para medir por ejemplo la abertura y longitud de grietas en una pared, o bien obtener pequeños detalles como inscripciones, de esculturas precolombinas. El tiempo por estación de escaneo es de 90 minutos.

\section{Usos geológico-ingenieril: Deslizamiento en la} Ruta Nacional $N^{\circ} 1$ kilómetro $44+400$

Hacia el año 2011 ocurrió un deslizamiento que afectó parte de la carretera de la Ruta Nacional $\mathrm{N}^{\circ} 1$ (RN 1), en el kilómetro 44+400, en el lado izquierdo de la vía en el sentido San José - San Ramón, frente a la Estación de Servicio Panamericana (Fig. 9A y 9B; coordenadas 454880 E - 1114130 N, Proyección CRTM-05).

Las formaciones y unidades geológicas presentes en las inmediaciones del sitio del deslizamiento analizado, corresponden con materiales de origen volcánico y sedimentario. Las litologías presentes corresponden con basaltos, andesitas, lavas, tobas y tobitas muy alteradas del Grupo Aguacate, tobas dacíticas con biotita de la Formación Alto Palomo, ignimbritas de la Formación Tiribí y sedimentos lacustres de la Unidad Lacustre Palmares.

La Figura 9C muestra un sector del mapa geológico de la hoja topográfica 1: 50000 Naranjo (Huapaya \& Rojas, 2012), que incluye el sitio, y 


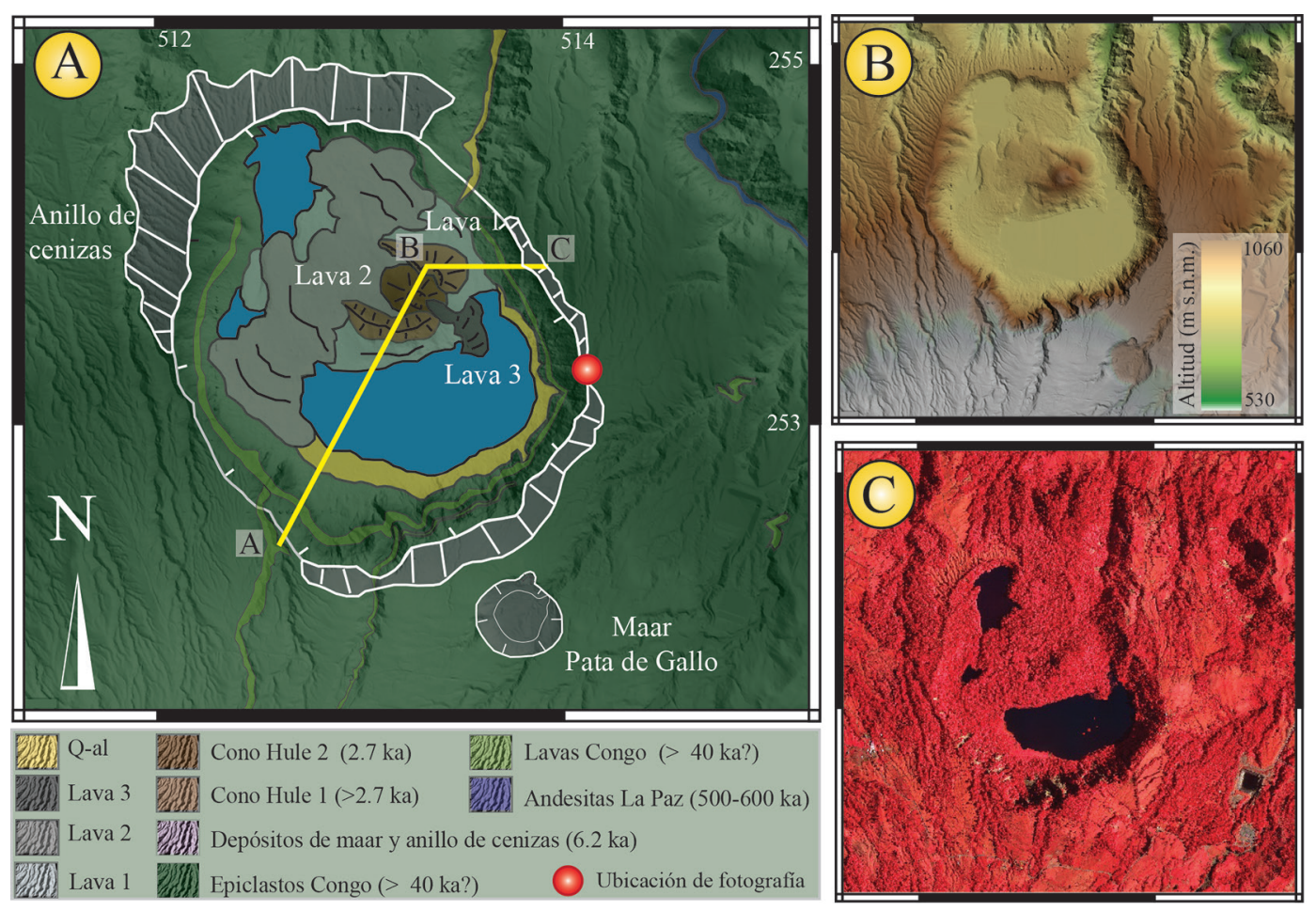

Fig. 7: A) Mapa geológico de los maares Hule y Pata de Gallo, con interpretación de las estructuras descubiertas gracias al MED generado con información lídar, el perfil ABC se muestra en la figura 8. B) Modelo de elevación digital generado con una nube de puntos de información lídar de resolución de 4 puntos/ $\mathrm{m}^{2}$ en promedio. C) Ortofotografía con un seudocolor infrarojo.

en el cual ya se habían incluido al menos dos deslizamientos que afectan directamente la RN 1 y otros en las laderas de la zona.

El deslizamiento principal y estudiado aquí, ocurrió en un sitio donde afloran materiales de la Unidad Lacustre Palmares, la cual está constituida por sedimentos finos laminados que presentan un color blancuzco, con presencia de pómez de color café y diatomitas. Tiene un espesor observado de hasta $8 \mathrm{~m}$ y en ella se han encontrado improntas de plantas, así como restos óseos de vertebrados (Huapaya \& Rojas, 2012 \& Pérez 2013). Los otros deslizamientos ubicados en esta zona también se sitúan en la misma unidad geológica, y la RN 1 corta a la unidad en varios otros sitios, como los que ve en la Figura 9C. Debido a las características geotécnicas de estos materiales, se apunta a que los taludes tengan una susceptibilidad litológica alta a generar nuevos eventos disparados por exceso de lluvias o eventos sísmicos y que puedan afectar la RN 1 .
La sección de la RN 1 donde se ubican los deslizamientos acá mencionados, se encuentra en el sector noreste del borde interno de la Caldera de Palmares. Esta geoforma (Fig. 9D), consiste en una depresión topográfica casi circular originada por actividad volcánica o bien por efectos erosivos, asunto que aún es discutible. Las laderas internas de esta caldera presentan pendientes promedio de $16-35^{\circ}$, y en algunos tramos, $>35^{\circ}$. Estos valores de pendientes fuertes y muy fuertes, están relacionados con procesos denudacionales intensos (deslizamientos), y erosión de suelos, por lo que este sitio tiene una alta susceptibilidad por pendientes a generar deslizamientos.

En febrero del 2014, utilizando el equipo de escaneo lídar del PITRA-Lanamme-UCR, se obtuvo el registro digital tridimensional de la condición actual del deslizamiento (Fig. 10). El equipo se programó en una resolución alta, con lo que se pudo capturar detalles en el talud afectado y la estación de servicio ubicada al otro costado de la carretera. 

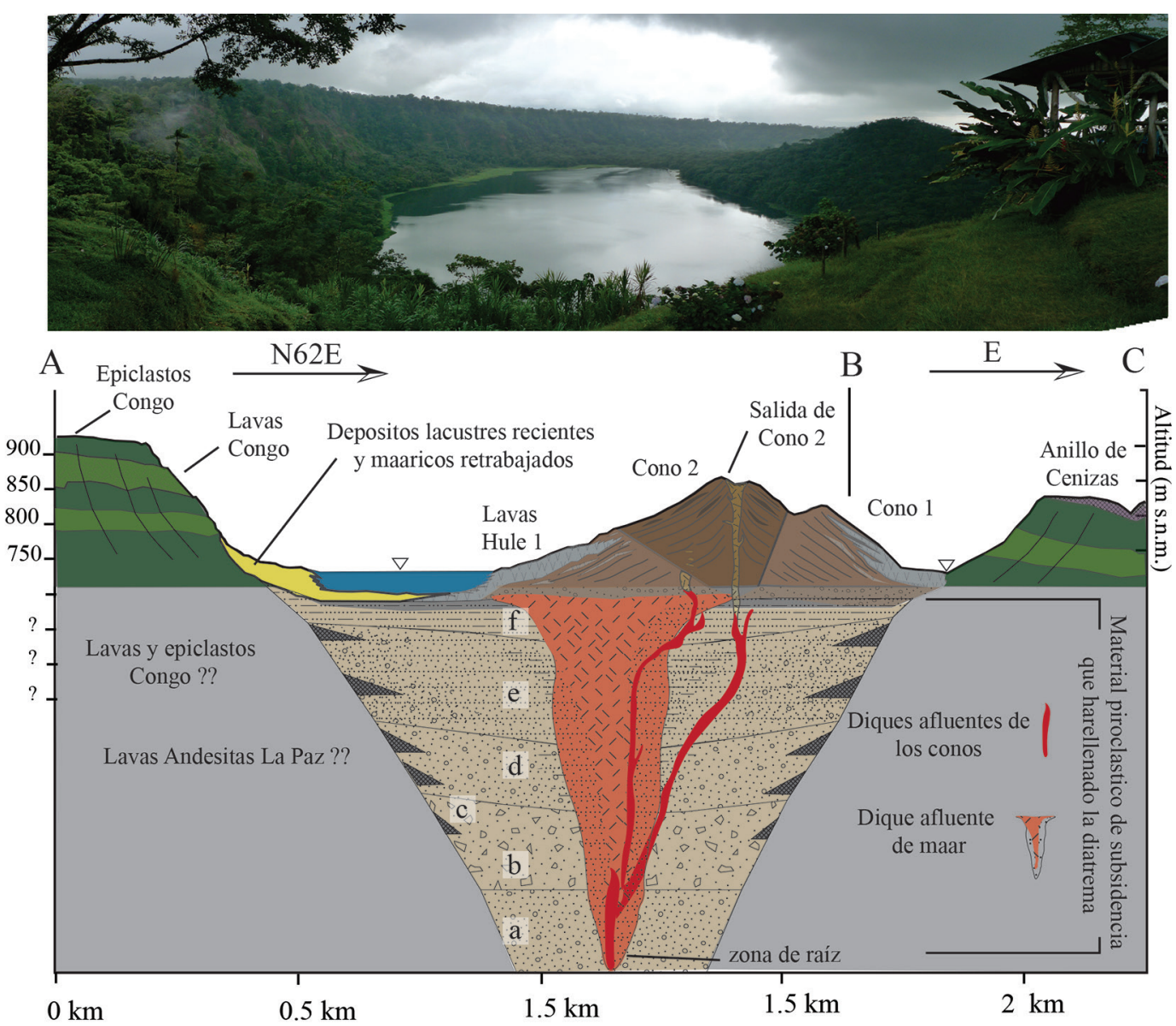

Fig. 8: Fotografía de la Laguna de Hule y perfil geológico con interpretación sobre la posible estructura interna de este maar, basado en los modelos de formación y erosión de maares de Kurszlaukis \& Fulop (2013), a) zona de resedimentación por colapso del cráter original del maar y cenizas, b) material de colapso más grueso del cráter del maar, c) anillos de ceniza que se formaron a medida que el maar iba creciendo, d) sedimentación de materiales medios hasta lapilli e) sedimentación de materiales muy finos y ceniza, f) sedimentación de materiales lacustres. El perfil topográfico, para generar esta figura proviene del MED lídar.

Para realizar dicho levantamiento, se montaron 2 estaciones, cada una en los extremos del deslizamiento a una distancia de $23,2 \mathrm{~m}$. Para poder unir dichos levantamientos entre sí usando el programa de la estación, se montaron también 2 puntos de amarre, equidistante cada uno de las estaciones mencionadas. Con el escáner configurado en un nivel de precisión alto, tomó aproximadamente 4 horas realizar todo el trabajo del levantamiento topográfico.

Con la información generada, se pudieron hacer mediciones que comprueban que los vehículos que actualmente transitan el carril hacia San José lo hacen a una distancia de apenas 2,1 $\mathrm{m}$ del borde del deslizamiento, lo que constituye un peligro para la seguridad de los usuarios ante la posibilidad de que un vehículo se salga de la vía (Fig. 11). Adicionalmente, las cargas dinámicas inducidas por los vehículos en el pavimento provocan desprendimiento del material en el talud, acelerando el deterioro y disminuyendo la distancia entre los vehículos y el borde del deslizamiento.

Mediante un perfil transversal del deslizamiento realizado con la información lídar, se demostró que una de las secciones más críticas estudiadas, presenta un sector en la parte superior casi 


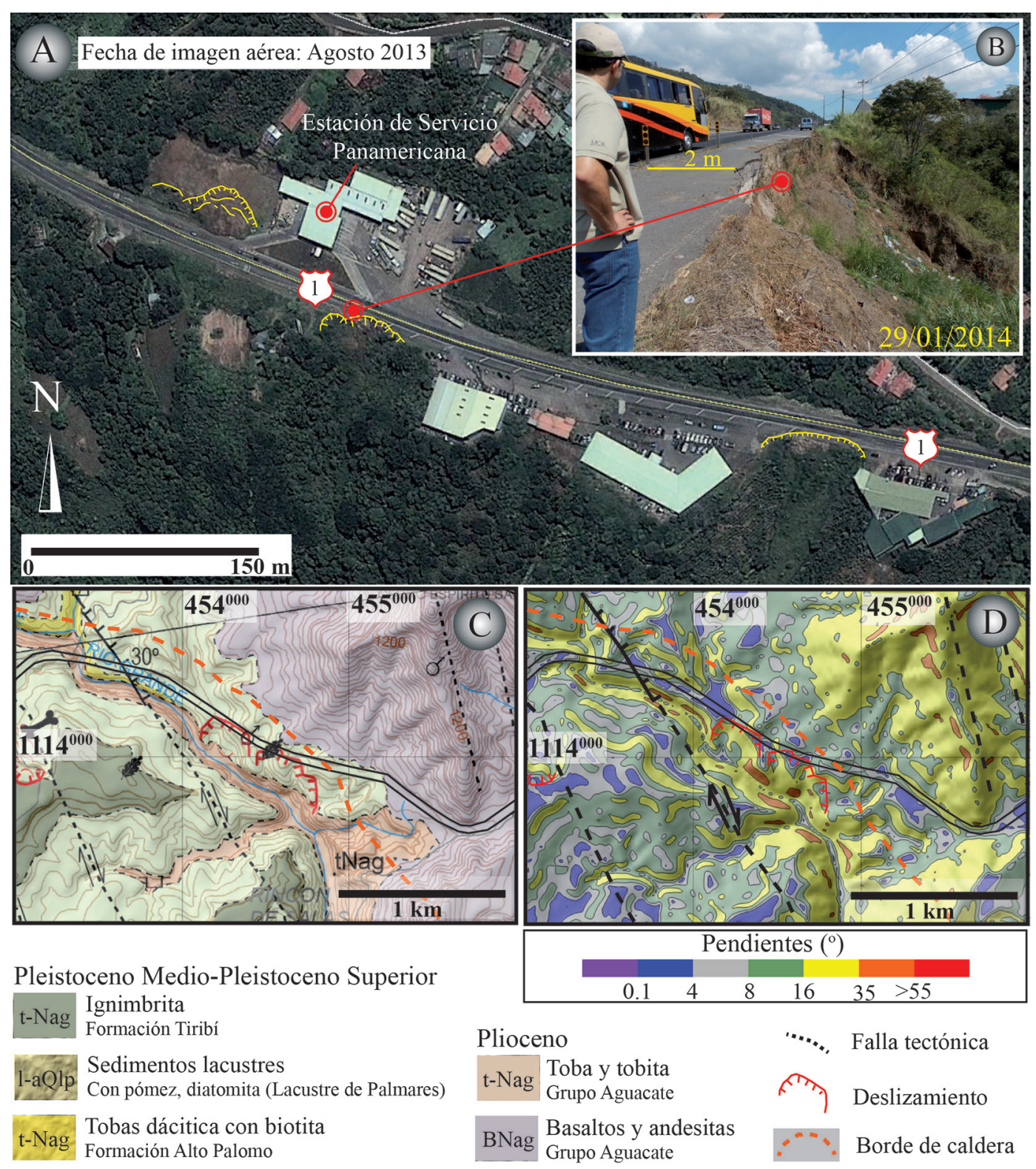

Fig. 9: A) Ubicación del deslizamiento en la RN 1, km 44+400 en la imagen de Google Earth, donde se observan tres deslizamientos, dos de ellos en los taludes del costado sur de la RN1 y otro en un talud al costado norte de la ruta, contiguo a la Estación de Servicio Panamericana. B) Fotografía de detalle del deslizamiento principal. C.) Sección del mapa geológico de la hoja Naranjo, donde se observa la relación entre los deslizamientos y la unidad de sedimentos lacustres. D.) Mapa de pendientes donde se aprecia la sección de la RN 1 construida en los taludes internos de la parte noreste de la Caldera de Palmares, con fuertes pendientes.

vertical, con una caída de aproximadamente $4 \mathrm{~m}$. Luego se identificó un tramo de transición cercano a los $5 \mathrm{~m}$ de altura y aproximadamente $7 \mathrm{~m}$ de ancho. En la parte inferior de este talud se podría explorar la factibilidad de cimentar una eventual obra de estabilización. Los datos anteriores son 

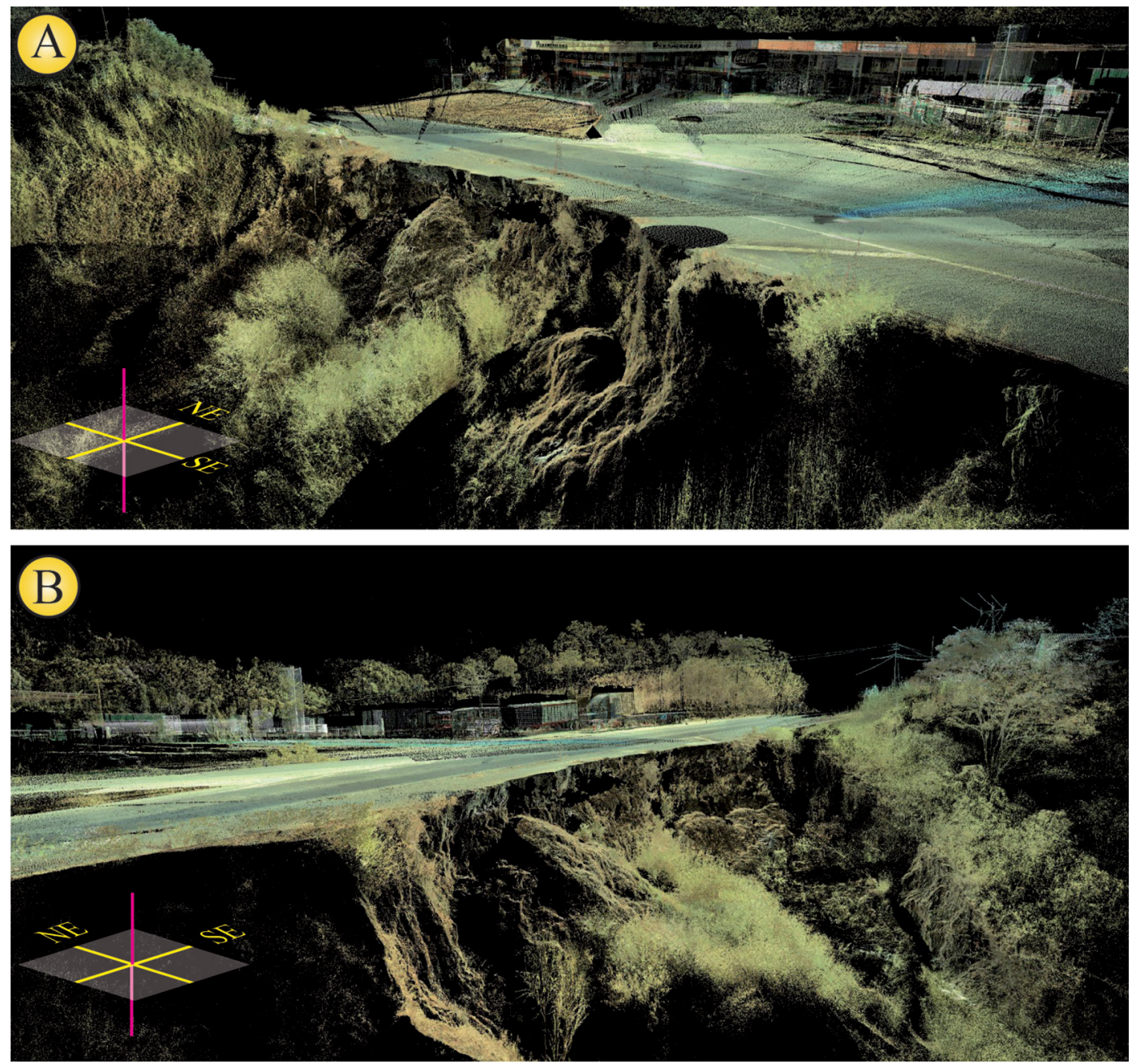

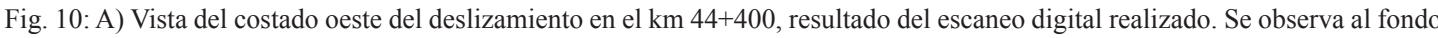
la Estación de Servicio Panamericana. B) Vista del costado este del deslizamiento. Se aprecia el talud generado por el deslizamiento, el cual soporta actualmente la estructura del pavimento.

esenciales para su diseño, que deben tomar las características geotécnicas del material y la disposición geométrica del deslizamiento.

\section{Uso arqueológico: Esfera precolombina de la Facultad de Ciencias Agroalimentarias}

El 29 de agosto del 2013 se realizó un escaneo lídar de la esfera precolombina que se encuentra en la Facultad de Ciencias Agroalimentarias, en la sede central de la Universidad de Costa Rica, en San Pedro de Montes de Oca. Para ello, se utilizó el Escáner Láser 3D con una resolución alta, que permitió crear modelos tridimensionales de precisión milimétrica en un tiempo relativamente corto.

Se montaron 4 estaciones, cada una en un cuadrante de un círculo imaginario con un radio aproximado de 5 metros. Para poder unir los levantamientos entre sí usando el programa de la estación, se montaron también 4 puntos de amarre, 
equidistante cada uno de las estaciones mencionadas y a una distancia de $3 \mathrm{~m}$ de la esfera. Con el escáner configurado en un nivel de precisión alto, tomó aproximadamente 3 horas realizar todo el trabajo.

Además del trabajo con el escáner lídar, se procedió a limpiar una sección rectangular, para realizar una descripción macroscópica de la mineralogía de la roca que se utilizó para hacer esta esfera. La sección que se limpió está ubicada en la parte central de la pieza arqueológica, y se utilizó un cepillo de raíz, agua y jabón común para remover líquenes, polvo y suciedad en general. En otras partes de la esfera se observaron líquenes de hasta $10 \mathrm{~cm}$ de diámetro e insectos adheridos a la roca. Los detalles se muestran en el Cuadro 2, y ha resultado ser una roca plutónica (fenodiorita o fenogabro).

Del modelo en tres dimensiones que se generó de la esfera precolombina, se obtuvieron un poco más de 32 millones de puntos, en un diámetro máximo de 1,956 metros, con un error máximo de $2 \mathrm{~mm}$, el cual representa la precisión del modelo obtenido. Con el diámetro máximo obtenido se fabricó una esfera sintética para compararla con la esfera precolombina y ver posibles diferencias.

En la Figura 12, se muestran ambas esferas superpuestas, las zonas que se observan en color gris corresponden a lugares donde la esfera de piedra es ligeramente más pequeña que la esfera sintética. Considerando que esta esfera fue construida hace varios siglos, tiempo en el cual ha sufrido variaciones termales de manera diaria, así como la exposición a los elementos (lluvia, ataques químicos y biológicos por parte de la vegetación, y en las últimas décadas, contaminación por parte de los vehículos que circulan a escasa distancia frente a la facultad), es de destacar el estado de conservación y especialmente, la poca desviación de forma que presenta.

El error medio obtenido del ajuste entre la nube de puntos y la esfera es de $0 \mathrm{~mm}$ con una desviación estándar de $7 \mathrm{~mm}$ (aproximadamente $0,3 \%$ del diámetro), lo cual le da validez al modelo de "esfera perfecta" del diámetro establecido.

Comparando entonces la ubicación de los puntos de la nube con dicha esfera, el error medio absoluto que se obtiene (y por tanto, la desviación promedio que presenta el monumento con respecto a la esfera ideal, las áreas grises de la Figura 12 A) es de $5 \mathrm{~mm}$ ( $0,25 \%$ del diámetro); a esta estimación del error se le debe agregar $\pm 2 \mathrm{~mm}$ que fue el error reportado por el escáner al momento de crear el modelo. El último error reportado, denominado error máximo absoluto, corresponde con el error máximo del modelo con respecto a dicha esfera, arrojó un resultado de $27,1 \mathrm{~cm}$, y que corresponde con la parte enterrada de la pieza arqueológica y que por tanto se puede descartar para este estudio.

Considerando las técnicas que se tenían en la época para la confección de tales objetos, un error de menos de $0,25 \%$ del diámetro es muy notable, difícilmente superable incluso en la actualidad. Lo anterior demuestra el nivel tecnológico que contaban nuestros antecesores amerindios, y la importancia de rescatar y estudiar más a fondo dicho patrimonio para las futuras generaciones.

Con toda la información recopilada en este escaneo y la descripción petrográfica se pudo calcular y estimar de otros parámetros de la esfera, como área, volumen así como de su peso aproximado con base en la densidad que tiene un gabro o una diorita (Cuadro 3).

\section{OTRAS APLICACIONES LÍDAR EN LA RED VIAL NACIONAL, TRABAJOS PRESENTES Y FUTUROS}

En Lanamme-UCR, se está trabajando en diferentes proyectos con tecnología lídar, tanto con datos aéreos como información obtenida con el escáner terrestre. El objetivo principal de estos trabajos es generar insumos de altísima precisión y detalle que sirvan para poder mejorar las condiciones de la red vial nacional de Costa Rica y disminuir la vulnerabilidad en sitios específicos de las principales carreteras del país.

Hasta principios del 2014 se han realizado varios estudios con el escáner terrestre en diferentes taludes y deslizamientos de rutas nacionales. Además del caso de la RN 1 presentado en este trabajo, se han realizado otros escaneos en taludes de la RN 27 (San José - Caldera) y deslizamientos en la RN 613 (San Vito - Las Mellizas, Zona Sur). 
Cuadro 2

Composición petrográfica de la esfera precolombina, con base en descripción macroscópica

\begin{tabular}{cll}
\hline Textura & \multicolumn{1}{c}{ Descripción macroscópica } & Clasificación \\
\hline & Plagioclasas $(65 \%)$ : Color blancuzco, algunas con ligera \\
& pátina de óxidos de hierro (producidos por otros minera- \\
& les) sobre su superficie, son idiomórficas a hipidiomór- \\
& ficas, de $2 \mathrm{~cm} \times 2 \mathrm{~mm}, 5 \mathrm{~mm} \times 2 \mathrm{~mm}, 1,1 \mathrm{~cm} \times 1 \mathrm{~mm}$, \\
& $1,3 \mathrm{~cm} \times 2 \mathrm{~mm}$. Hornblendas $(30 \%)$, no son claramente Fenogabro o fenodiorita \\
Fanerítica, equigranular, homogénea & reconocibles, son idiomórficas a hipidiomórficas, entre Fen \\
& $1,5 \times 1 \mathrm{~mm}, 6 \mathrm{~mm} \times 1 \mathrm{~mm}, 9 \mathrm{~mm} \times 1 \mathrm{~mm}, 1,2 \mathrm{~cm} \times 1 \mathrm{~mm}$ \\
& Piroxenos $(5 \%)$, (augitas). xenomórficos, mm hasta un \\
& máximo de $2 \mathrm{~mm} \times 2 \mathrm{~mm}$, se observan algunas poro- \\
& sidades probablemente terciarias por abrasión mecánica \\
\hline
\end{tabular}

Otra de las aplicaciones que se le ha dado al equipo lídar terrestre, ha sido en el campo de la seguridad vial. Se han realizado escaneos en intersecciones y sitios problemáticos que por tener radios de giro reducidos en las esquinas, generaban accidentes de tránsito constantemente. A partir de los datos obtenidos se pudieron realizar cambios y mejoras en los diseños y en la ubicación del señalamiento vial para disminuir el número de accidentes.

En estructuras relacionadas con la red vial nacional, se ha trabajado en el escaneo de puentes, para determinar problemas estructurales como por ejemplo en el puente sobre el río Virilla de la RN 32 (conocido también como "Puente del Saprissa", por sus cercanías al estadio con ese nombre) para determinar las deformaciones que se han generado a lo largo de los años en la superficie de ruedo. Además se utilizaron datos lídar en el informe sobre el estado de la vulnerabilidad de alcantarillas asociadas con rutas nacionales de alto tránsito diario del Gran Área Metropolitana (GAM) (Naranjo et al., 2014).

Próximamente en el Lanamme-UCR se completarán estudios en los que se está aplicando la combinación de datos lídar terrestres y aéreos en rutas nacionales. Algunos casos son la RN 126, donde se dispararon miles de deslizamientos por el Terremoto de Cinchona de enero del 2009 y ya hay resultados preliminares (Ruiz et al., 2014), la RN 32 (Braulio Carrillo) donde anualmente se presentan múltiples eventos de remoción de masa disparados por lluvias intensas, y la ruta Sifón - La Abundancia (conocida como carretera
Naranjo-San Carlos), donde antes de concluida la construcción de la carretera ya se han presentado problemas de estabilidad en taludes.

Con las imágenes lídar aéreas, se están determinando zonas criticas con base en los mapas de pendientes y modelos de susceptibilidad al deslizamiento. Los puntos más problemáticos se están escaneando en tierra para generar modelos en tres dimensiones. Los datos lídar, junto con la información geológica y datos mecánicos de los suelos y macizos rocosos son vitales para generar un modelo geotécnico. Con toda esta información se están desarrollando los diseños de estabilización o intervención de los taludes problemáticos. Posteriormente a la intervención y trabajos de estabilización, se dará seguimiento al sitio con escaneos y mediciones lídar en tierra.

Cuadro 3

Resumen de los datos obtenidos para esfera precolombina de la faculta de agronomía

\begin{tabular}{cc}
\hline Característica & Cantidad \\
\hline $\begin{array}{c}\text { Nube de puntos } \\
\text { de escaneo lídar }\end{array}$ & 32174356 \\
Diámetro de esfera & $1,956 \mathrm{~m}$ \\
Área & $12,28 \mathrm{~m}^{2}$ \\
Volumen & $3,918 \mathrm{~m}^{3}$ \\
Tipo de material & Gabro- diorita \\
Densidad del material & $2,7-3,3 \mathrm{~g} / \mathrm{cm}^{3}$ (posible) \\
Peso estimado & $10,50-12,95$ \\
& toneladas métricas \\
\hline
\end{tabular}




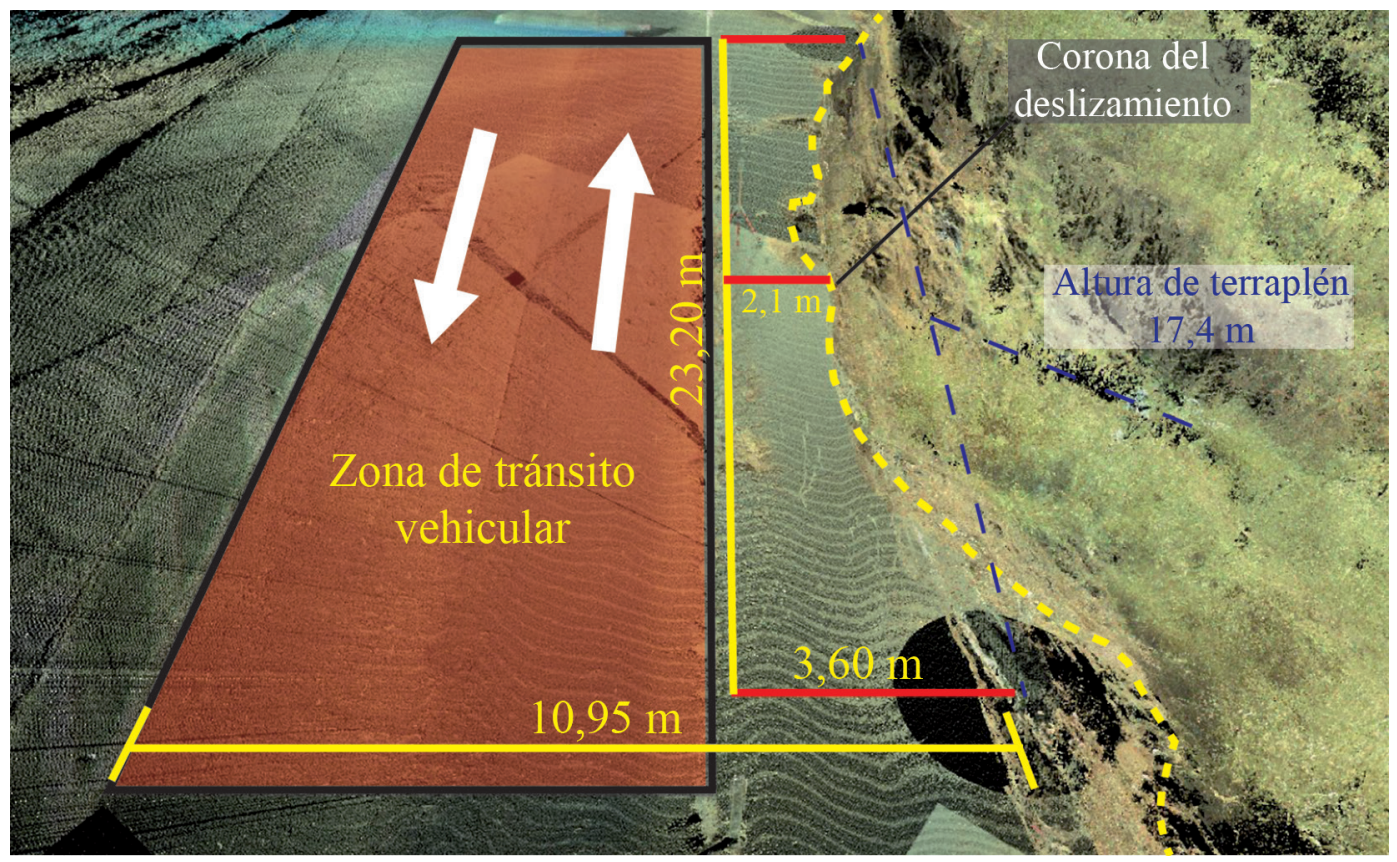

Fig. 11: Vista superior del deslizamiento, que muestra la cercanía de la corona del deslizamiento con la zona de tránsito vehicular y otras dimensiones obtenidas mediante el procesamiento de la información del equipo de escaneo digital.

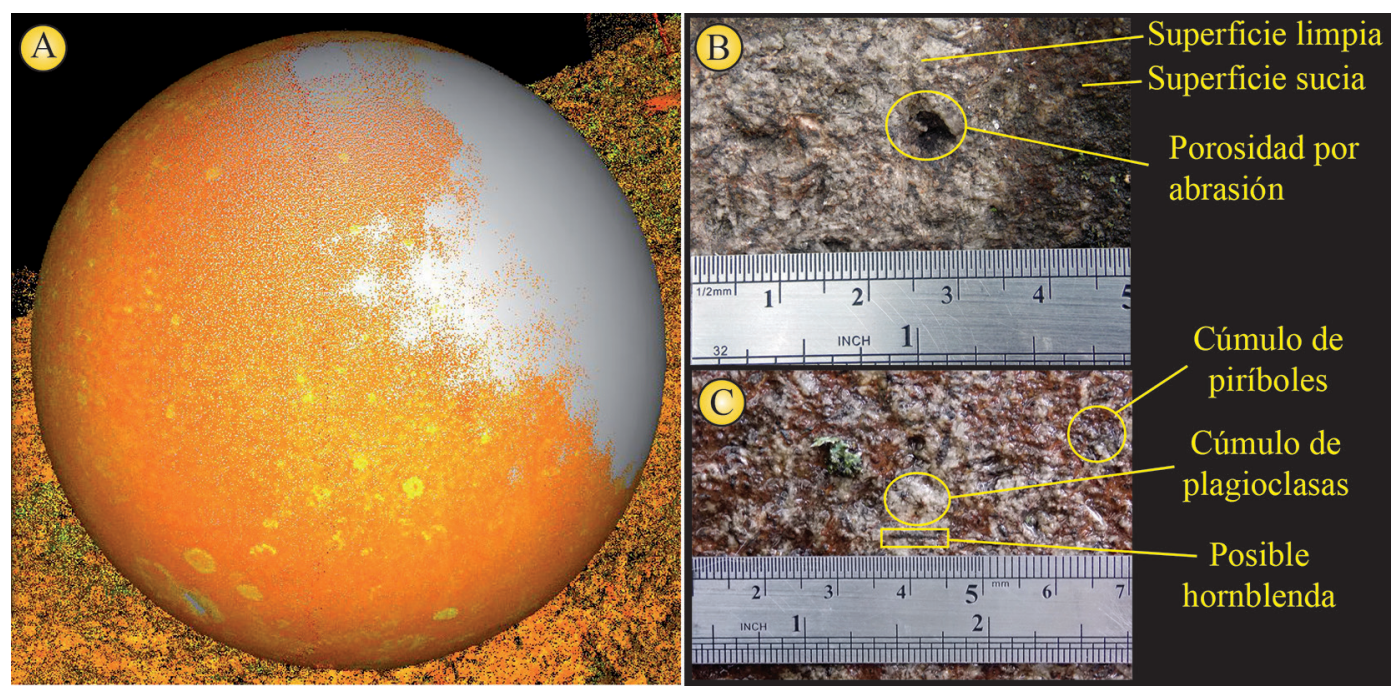

Fig. 12: A) Comparación entre las esferas escaneada (anaranjada) y sintética (color gris). B) Sección de la esfera analizada, que muestra las diferencia entre la roca limpia y la roca sucia, y también un detalle de la porosidad que presenta probablemente terciaria por abrasión mecánica. C) Sección de la esfera donde se hizo el análisis petrográfico, la superficie aún se encuentra húmeda por el agua que se usó para limpiarla (por eso la coloración diferente con la anterior), donde se observan cúmulos de minerales de plagioclasas y piríboles. 


\section{CONCLUSIONES}

En este trabajo se ha realizado una pequeña reseña histórica sobre la evolución de la tecnología lídar, para comprender mejor cómo es que se han dado mejoras y adiciones de otras tecnologías (GPS, cámaras digitales, memorias de alta capacidad, etc.) hasta llegar a tener los equipos lídar actuales, que son los que se utilizaron en los casos de estudio presentados aquí.

Con la información que se expone en este trabajo sobre el funcionamiento y los parámetros técnicos de la adquisición y las diferentes resoluciones de datos lídar aéreos y terrestres, se ha generado un insumo detallado, para que otros potenciales usuarios de esta tecnología puedan contar con algunos datos y ejemplos gráficos, que los ayude en la toma de decisiones antes de contratar un vuelo o un escaneo con un equipo lídar en tierra.

Se exponen los principales resultados ligados con tecnología lídar, de cuatro casos de estudio en Costa Rica. Se presentaron los principales resultados ligados con tecnología lídar, de un caso de estudio histórico, pero muy poco conocido a nivel nacional. El estudio de Sheets et al. (1991), fue una de las primeras aplicaciones a nivel mundial de lídar en el campo de la arqueología y ocurrió en la década de los años 1980 en el noroeste de Costa Rica. Aquí se expuso información sobre trillos y senderos precolombinos nunca antes vistos. Este estudio mostró la aplicación de poder eliminar la vista de la vegetación de un área específica y poder encontrar anomalías lineales de poca anchura que posteriormente fueron confirmadas en el campo, como algunos de los primeros sistemas de transporte y comunicación de los antiguos habitantes de la zona del volcán Arenal, hace más de 2000 años.

El segundo caso de estudio presentado y anteriormente trabajado por Alvarado et al. (2011), muestra las ventajas de utilizar lídar aéreo para realizar trabajos de mapeo, interpretaciones geomorfológicas y geológicas, que posteriormente fueron corroboradas en el campo. En este caso, gracias a los MED de la zona del cráter explosivo de Laguna Hule (norte del macizo del Volcán Poas) se lograron identificar dos conos piroclásticos, uno construido sobre el otro y tres pequeños campos de coladas y materiales de lava asociados a los conos.

En el tercer caso de estudio, se muestra una aplicación del escáner lídar terrestre para caracterizar un deslizamiento en la RN 1 en el sector de Palmares y que actualmente está poniendo en peligro a los usuarios de esta ruta. El modelo en tres dimensiones generado y los valores reales de su ancho, largo y profundidad, sirven junto con la información geológica recolectada en el sitio para el diseño de una solución definitiva en este punto. La metodología utilizada en este caso, se puede usar en otros sitios que presenten situaciones similares.

El último caso de estudio de este trabajo, es un ejemplo de la aplicación de la tecnología lídar terrestre a una estructura arqueológica relativamente pequeña, de mucha importancia y en la que no es permitida su manipulación física, como lo es una esfera precolombina. Aquí se pudo escanear esta pieza y comparar su forma con una esfera sintética perfecta. Se realizó un estudio petrográfico macroscópico para determinar la mineralogía de esta pieza y definir el tipo de roca que se utilizó. Posteriormente, con la combinación de los datos paramétricos obtenidos a partir del escáner lídar y la densidad posible a partir del tipo de roca que constituye la esfera, se logró estimar el peso de la obra. Se recomienda realizar el mismo procedimiento presentado aquí, para otras obras con características y limitaciones de manipulación similares a este caso, ya sean de índole arqueológica, patrimonial, geológica o industrial.

Se espera que en los próximos años sean más frecuentes los resultados de otros casos de estudio donde se utilice la tecnología lídar (aérea, terrestre o ambas). Esto debido a que sus costos serán cada vez más accesibles, se facilitará la transferencia de información entre instituciones y que cada vez más, van surgiendo nuevas aplicaciones en diferentes campos para esta tecnología de láser. 


\section{AGRADECIMIENTOS}

Agradecemos a Julio César Moraga Peralta por la revisión y comentarios de este articulo. A la empresa Aerodiva por facilitarnos varios ejemplos de resoluciones de imágenes lídar. Al ICE por haber permitido usar las imágenes del área del corredor del río Sarapiquí en el macizo del volcán Poás. Asimismo a la Facultad de Ciencias Agroalimentarias de la Universidad de Costa Rica, por permitir trabajar con la esfera precolombina ubicada en sus jardines.

\section{REFERENCIAS BIBLIOGRÁFICAS}

ALVARADO, G. E., SOTO, G. J., SALANI, F. M., RUIZ, P. \& HURTADO, L., 2011: The formation and evolution of Hule and Río Cuarto maars, Costa Rica.- J. Volcanol. Geoth. Res. 201: 342-356.

CAMPBELL, J. B. \& WYNNE, R. H., 2011: Introduction to Remote Sensing [5th ed].667 págs. The Guilford Press, New York.

FLOOD, M., 2001: Laser altimetry: From Science to Commercial LiDAR Mapping.Photogrametric Engineering and Remote Sensing, 67: 1209-1217.

GOYER, G. \& WATSON, R., 1963: The laser and its application to Meteorology.- Bul. Am.Meteor. Soc. 44(9): 564-575.

HILL, J. M., GRAHAM, L. A., \& HENRY, J. R., 2000: Wide-Area topographic mapping using airborne light detection and ranging (LIDAR) technology.- Photogrammetric Engineering and Remote Sensing, 66: 908-914, 927, 960.

HUAPAYA, S. \& ROJAS, V., 2012: Mapa Geológico de Hoja Naranjo (3346-III).Escala 1: 50 000, Dirección de Geología y Minas, San José, Costa Rica.
HYPPÄ, J., WAGNER, W., HOLLAUS, M., \& HYPPÄ, S., 2009: Airborne laser mapping.- En: WARNER, T. A.; DUANE, M. \& FOODY, G. M. (eds): Sage Handbook of Remote Sensing.- Sage, London: 199-211.

KURSZLAUKIS, S. \& FULOP, A., 2013: Factors controlling the internal facies architecture of maar-diatreme volcanoes.- Bull. Volcanol. 75(761), DOI 10.1007/s00445013-0761-y.

MORA, S., SABORIO, J., ASTÉ, J. P., PREPETIT, C., JOSEPH, V., \& MATERA, M., 2012: Slope instability hazard in Haiti: Emergency assessment for a safe reconstruction.- En: EBERHARDT, E., FROESE, C., TURNER, K. \& LEROUEIL, S. (eds): Landslides and Engineered Slopes: Protecting society through improved understanding. CRC Press, Londres.

NARANJO, R., RUIZ, P., \& SANABRIA, J., 2014: Metodología para análisis de vulnerabilidad estructural y del sitio de las alcantarillas de la GAM.- Congr. de Ingeniería Civil, 20-22 de Mayo 2014, San José, Costa Rica: 352-359

NATIONAL AERONAUTICS AND SPACE ADMINISTRATION (NASA), 2009: Apollo 15 Flight Journal, Apollo Flight Journal project.- http:/history.nasa.gov/ ap15fj/ [Consulta: 12 de marzo de 2014].

NELSON, R., SWIFT, R. \& KRABILL, W., 1988: Using airborne laser to estimate forest canopy and stand characteristics.- J. Forestry, 86: 31-38.

NILSSON, M., 1996: Estimation of tree heights and stand volume using an airborne Lidar system.- Remote Sensing of Environment, 56: 1-7. 
PÉREZ, E. A., 2013: Los mamíferos de la localidad de Puente de Piedra (Xenarthra, Glyptodontidae, Artiodactyla, Camelidae, Lamini) Grecia, Provincia de Alajuela, Costa Rica.- Rev. Geol. Amér. Central, 49: 33-44.

ROMANO, M. E., 2004: Inovation in Lidar processing.- Photogrammetric Engineering and Remote Sensing, 70: 1201-1206.

RUIZ, P., GAZEL, E., ALVARADO, G. E., CARR, M. J. \& SOTO, G. J., 2010: Caracterización geoquímica y petrográfica de las unidades geológicas del macizo del volcán Poás, Costa Rica.- Rev. Geol. Amér. Central, 43: 37-66.

RUIZ, P., SOTO, G. J., \& BARRANTES, R., 2014: Uso de imágenes lídar en el estudio de la vulnerabilidad de la red vial nacional, caso de estudio Ruta No 126 Lídar en la ruta 126 - Congr. de Ingeniería Civil, 2022 de Mayo 2014, San José, Costa Rica: 315-326.

SHEETS, P. \& SEVER, T., 1988: High tech wizardry.- Archeology, 41(6): 28-35.

SHEETS, P., HOOPES, J., MELSON, W., MCKEE, B., SEVER, T., MARILYNN, M., CHENAULT, M. \& BRADLEY, J., 1991: Prehistory and volcanism in Arenal area, Costa Rica.- J. Field Archaeol. 18: 445-465.

UNITED STATES DEPARTMENT OF AGRICULTURE (USDA), 2012: Fusion/ LDV: Software for lidar data analysis and visualization.- 175 págs. Fusion version 3.42., http://forsys.cfr.washington.edu/fusion/FUSION_manual.pdf. 
